Word count: Abstract - 289, Text - 3229

\title{
Post-viral parenchymal lung disease following COVID-19 and viral pneumonitis hospitalisation: A systematic review and meta-analysis
}

Short title: Systematic review and meta-analysis of Post-COVID sequelae

Laura Fabbri ${ }^{1,2,3}$, Samuel Moss ${ }^{1,2}$, Fasihul Khan ${ }^{1,2}$, Wenjie $\mathrm{Chi}^{4}$, Jun Xia ${ }^{5}$, Karen A. Robinson ${ }^{6}$, Alan Smyth ${ }^{2,7}$, Gisli Jenkins ${ }^{1,2,3}$, lain Stewart ${ }^{1,2,3}$

1. Division of Respiratory Medicine, University of Nottingham, Nottingham, UK.

2. Nottingham Biomedical Research Centre, National Institute for Health Research, UK

3. National Heart and Lung Institute, Imperial College London, London, UK.

4. Systematic Review Solutions Ltd, Ingenuity Centre, Nottingham, UK

5. Institute of Mental Health, University of Nottingham, Nottingham, UK

6. Department of Medicine, Johns Hopkins School of Medicine, Johns Hopkins University, US

7. Division of Child Health, Obstetrics \& Gynaecology, University of Nottingham, Nottingham, UK

Correspondence to:

Dr lain Stewart, Guy Scadding Building, Imperial College London, SW3 6LY; iain.stewart@imperial.ac.uk

\section{Key words:}

COVID19, CT, gas transfer, lung sequelae, restrictive impairment, pulmonary fibrosis,

\author{
Abbreviations: \\ $\mathrm{CT}$ : computed tomography \\ DLCO: diffusing capacity for carbon monoxide \\ FEV1: forced expiratory volume in the first second \\ FVC: forced vital capacity \\ TLC: total lung capacity
}

Funding: National Institute for Health Research (NIHR).

Summary competing interests: LF, SM, FK, WC, JX, KR, AS and IS report no competing interests relating to the manuscript, GJ reports NIHR BRC salaries, studentships, professorship (RP-2017-08-ST2-014)

Declarations: this manuscript is available on a preprint server, DOI: 10.1101/2021.03.15.21253593 


\section{Abstract}

Background: Approximately half of COVID-19 survivors present persisting breathlessness, which may include development of pulmonary fibrosis.

Research Question: What is the prevalence of long-term radiological and functional pulmonary sequelae of parenchymal lung disease following hospitalisation with COVID-19 and other viral pneumonia?

Study design and methods: We performed systematic review and random effects meta-analysis of studies in adults hospitalised with SARS-CoV-2, SARS-CoV, MERS-CoV, or Influenza pneumonia and followed within 12 months from discharge. Searches were run on MEDLINE and Embase, updated 29 July 2021. Primary outcomes were proportion of 1) radiologic sequelae at CT scans; 2) restrictive impairment; 3) impaired gas transfer. Heterogeneity was explored in meta-regression.

Results: Ninety-five studies were included for qualitative synthesis, of which 70 were suitable for metaanalysis, including 60 studies of SARS-CoV-2 with a median follow up of 3 months. In SARS-CoV-2 the overall estimated proportion of inflammatory changes during follow up was $0.50\left(95 \% \mathrm{Cl} 0.41\right.$ to $\left.0.58, \mathrm{I}^{2}=94.6 \%\right)$, whilst fibrotic changes were estimated at $0.29\left(95 \% \mathrm{Cl} 0.22\right.$ to $\left.0.37, \mathrm{I}^{2}=94.1 \%\right)$. Inflammatory changes reduced compared with CTs performed during hospitalisation $(-0.47 ; 95 \% \mathrm{Cl}-0.56$ to -0.37$)$, whereas no significant resolution was observed in fibrotic changes $(-0.09 ; 95 \% \mathrm{Cl}-0.25$ to 0.07$)$. Impaired gas transfer was estimated at $0.38\left(95 \% \mathrm{Cl} 0.32\right.$ to $\left.0.44, \mathrm{I}^{2}=92.1 \%\right)$, which was greater than estimated restrictive impairment $\left(0.17 ; 95 \% \mathrm{Cl} 0.13\right.$ to $\left.0.23, \mathrm{l}^{2}=92.5 \%\right)$. High heterogeneity means that estimates should be interpreted with caution. Confidence in the estimates was deemed low due to the heterogeneity and because studies were largely observational without controls.

Interpretation: A substantial proportion of radiological and functional sequelae consistent with parenchymal lung disease are observed following COVID-19 and other viral pneumonitis. Estimates of prevalence are limited by differences in case mix and initial severity. This highlights the importance of extended radiological and functional follow-up post hospitalisation.

PROSPERO registration: CRD42020183139 (April 2020) 


\section{Introduction}

Since COVID-19, the disease caused by SARS-CoV-2, was declared a global pandemic, ${ }^{1}$ over 220 million individuals have been infected (September 2021). ${ }^{2}$ The clinical spectrum of COVID-19 is wide, and can range from asymptomatic or mild flu-like symptoms, to severe viral pneumonia, requiring hospital admission, oxygen administration, and mechanical ventilation. ${ }^{3}$ Emerging data suggest that approximately half of COVID-19 survivors experience a long-term multisystemic syndrome characterized by chronic breathlessness and other abnormalities. ${ }^{4-6}$ The causes for the persistent respiratory symptoms have not been clearly elucidated, however, post-mortem studies on COVID-19 patients have highlighted diffuse parenchymal alterations, with alveolar damage, exudation, and development of pulmonary fibrosis. ${ }^{7-9}$

Pulmonary fibrosis is characterised by a dysregulated remodelling of the lung parenchyma. It can occur after a lung injury, although the cause cannot always be identified. Viral agents are considered important insults, with scientific rationale to implicate their role in fibrosis pathogenesis, although empirical evidence that suggests they can promote chronic parenchymal lung disease is limited. ${ }^{10} 11$ Fibrotic sequelae have been highlighted in the follow up of SARS-CoV and MERS-CoV. ${ }^{12-14}$ Similarly, Influenza viruses have also been proposed to promote the development of pulmonary fibrosis. ${ }^{15,16}$

Given the exceptional rate of COVID-19 spread and the longer-term impact on quality of life, particularly breathlessness, it is possible that parenchymal lung abnormalities may be a long-term consequence in survivors. We undertook a systematic review and meta-analysis to assess the prevalence of lung sequelae in people hospitalised with viral pneumonitis, focusing on CT scans and pulmonary function tests as noninvasive diagnostic exams routinely used to assess the presence of lung abnormalities. ${ }^{17,18}$

\section{Methods}

\section{Search strategy and selection criteria}

The systematic review and meta-analysis was conducted in accordance with a protocol registered with the International Prospective Register of Systematic Reviews (PROSPERO) on $30^{\text {th }}$ April 2020 (registration number CRD42020183139). The review has been reported following PRISMA and PICO guidelines. ${ }^{19,20}$ 
It is made available under a CC-BY-NC-ND 4.0 International license .

All original research reporting outcomes in populations of hospitalized adult patients (aged $>18$ ) with presumed or confirmed viral infection by SARS-CoV-2, SARS-COV, MERS-CoV or Influenza viruses were considered eligible for inclusion. No intervention was assessed relative to a control group. Comparisons were made between radiological sequelae types and metrics of lung function impairment, and compared with findings during hospitalisation where available. The pre-specified primary outcomes within 12 months of hospitalisation were: 1) presence of radiologic sequelae at follow-up CT scans; 2) presence of restrictive lung function impairment; 3) presence of reduced diffusing capacity for carbon monoxide ( $\mathrm{DL}_{\mathrm{co}}$ ). Inflammatory radiological findings were defined as ground-glass opacification or consolidation. Fibrotic radiological findings were defined as either reticulation, lung architectural distortion, interlobular septal thickening, traction bronchiectasis, or honeycombing. Restrictive lung impairment was defined as a total lung capacity $(T L C)<80 \%$ predicted value or forced vital capacity $(F V C)<80 \%$ predicted value with normalto-high FEV1/FVC ratio. Impaired gas transfer was defined as percent predicted $\mathrm{DL}_{\mathrm{CO}}<80 \%$.

Searches were performed in MEDLINE (1946 to latest), Embase (1974 to latest), and Google Scholar. Hand searches were conducted of the reference lists of eligible primary studies, and relevant review articles. No language criteria were applied. Pre-prints, abstracts, and non-original studies were excluded. Searches were last updated on $29^{\text {th }}$ of July 2021 . Searches were carried out using patient-related, treatment-related, and outcomes-related terms (Supplementary Figure 1). Titles and abstracts were screened in duplicate, followed by full-text review. Disagreements between reviewers were resolved by consensus with a third reviewer.

\section{Data analysis}

Data from the selected articles were extracted independently using a proforma by reviewers and mutually confirmed. Extracted data included study design, viral agent, methods of diagnosis, participant demographics, severity of acute infection (ventilatory requirements), as well as CT and lung function outcomes. Baseline investigations were defined as those performed during hospitalization, and follow-up as obtained after discharge; baseline data were only extracted where studies reported follow-up. If more than one follow-up visit was reported, the most complete sample size followed by the latest examination 
It is made available under a CC-BY-NC-ND 4.0 International license .

within 12 months from discharge was extracted in a hierarchical manner. Where data were not reported in the text, we contacted corresponding authors. Absolute values of the number of people meeting outcome criteria and number of people with exam results available were extracted as numerator and denominator, respectively.

Meta-analyses of proportions were performed where sufficient studies reported data, enabling an estimation of the prevalence of outcomes. Cohorts with fewer than ten cases (SARS-CoV, Influenza) or 25 cases (SARS-CoV-2) were excluded from quantitative synthesis owing to risk of selection bias when estimating proportions. Separate analyses were performed in each viral subtype (SARS-CoV-2, SARS-CoV, Influenza) and according to the type of radiological (inflammatory, fibrotic) or physiological (restrictive impairment, impaired gas transfer) outcome. Quantitative synthesis and random effects meta-analysis were performed in Stata SE16 (TX: StataCorp LLC) using the metaprop command, which computes 95\% confidence intervals based on binomial distribution and applies the Freeman-Tukey double arcsine transformation to support inclusion of observations of $0 \%$ and $100 \% .{ }^{21}$ Heterogeneity was assessed with $\mathrm{I}^{2}$; we report all estimates regardless of heterogeneity.

For SARS-CoV-2 studies, meta-regression was performed to assess the residual heterogeneity after adjustment for key study characteristics, timing of follow-up (months), severity of cohort (mild, moderate, severe), prospective design, evidence of selection bias (strict inclusion criteria based on indication for CT or where less than $60 \%$ of screened patients tested for outcomes), and approach to radiological classification (study author defined, or by review). Residual heterogeneity is assessed with $\mathrm{I}^{2}, \mathrm{R}^{2}$ is used to describe the variance in estimate explained by adjusted models. Reliability of estimates was assessed through sensitivity analysis in a restricted timeframe of 3-6 months follow up, and in sub analysis on studies that reported baseline quantifications.

The risk of bias in individual studies was assessed by two authors independently using appropriate assessment tools available from the CLARITY Group at McMaster University, ${ }^{22}$ through criteria specific for study design. We assessed exposure, the outcomes of interest, prognostic factors, interventions, adequacy 
It is made available under a CC-BY-NC-ND 4.0 International license .

of follow-up, and co-interventions. Randomized controlled trials were evaluated on random sequence generation, allocation concealment, blinding, adequacy of follow up, selective reporting, and other possible causes of risks of bias. Any disagreements were resolved by consensus with a third reviewer.

The quality of the evidence for each overall estimate of proportion was evaluated using the GRADE guidance. ${ }^{24}$ Retrospective observational studies were considered very low but could be upgraded, whilst prospective randomised studies were deemed high and could be downgraded. Analytical and publication risks of bias, inconsistency, indirectness, and imprecision in reporting were assessed. An overall judgement of 'high', 'moderate', 'low', or 'very low' was provided for the quality of the cumulative evidence for review outcomes.

\section{Results}

A total of 8321 records were identified from databases and hand searches. After title and abstract screening, 131 unique full-text manuscripts were assessed for eligibility, and 95 were included for qualitative synthesis (89 in English, 6 in Chinese). A total of 70 studies were included in the quantitative synthesis (Figure 1). Among the manuscripts included, 60 reported infections by SARS-CoV-2;, ;,23,25-83 18 by SARS-CoV; ${ }^{13,14,84-100} 1$ by MERS-CoV; ${ }^{101} 16$ by Influenza (11 subtype H1N1, 1 subtype H5N1, 1 subtype H3N2, 2 subtype H7N9 and 1 study both H1N1 and H7N9). ${ }^{102-117}$ All studies were observational in design, with the exception of a single randomized control trial. ${ }^{97}$ We focus reporting on changes subsequent to a SARS-CoV2 infection, quantitative synthesis for SARS-CoV and influenza are provided in supplemental material.

Individual SARS-CoV-2 study characteristics are presented in Table 1, and supplementary Table 1. Risk of bias assessment identified a number of limitations and possible causes of biases. A total of ten studies did not specify whether any serological or molecular testing was performed or referred to national guidelines at the time the study was conducted. Inclusion and exclusion criteria differed among studies, indicating that the severity of patients enrolled and care pathways followed may represent a possible selection bias. Few studies investigated the presence of previous respiratory diseases or considered it as an exclusion criteria, others were restricted to include only symptomatic patients or perform follow-up CT where there 
was a clinical indication, such as abnormalities on chest X-Ray (CXR) or reduced $\mathrm{DL}_{\mathrm{co}}{ }^{14,41,59,89}$ Details for all the studies are presented in Supplementary Tables 1-2; Supplementary Figure 2a -2b.

A total of 70 studies described thoracic CT findings, 46 were included in meta-analysis of radiological outcome of SARS-CoV-2. Causes of exclusion are listed in Figure 1. The median follow-up time was 3 months. Within 12 months following hospitalisation for SARS-CoV-2 infection, the overall estimated proportion of chest $\mathrm{CT}$ inflammatory changes was $0.50\left(95 \% \mathrm{Cl} 0.41\right.$ to $\left.0.58 . I^{2}=95.0 \%\right)$ on a total of $2670 \mathrm{CT}$ scans, whilst fibrotic changes had an estimated proportion of $0.29\left(95 \% \mathrm{Cl} 0.22\right.$ to $\left.0.37 . \mathrm{I}^{2}=94.1 \%\right)$ assessed on 2811 exams. Severe heterogeneity was observed in overall estimates (Figure 2). In meta-regression, adjustment for timing of follow-up significantly reduced the residual heterogeneity in overall estimate of inflammatory changes to $73.1 \%$ (Supplementary Table 4). Adjustment for timing reduced residual heterogeneity in the overall estimate of fibrotic change to $70.3 \%$. No other characteristics were observed to significantly contribute to heterogeneity, including severity of cohort, prospective design or risk of selection bias (Supplementary Tables 4-5).

We subsequently selected a restricted follow up timeframe of 3-6 months to minimise inconsistency in follow-up time (Supplementary Figure 3). Within this sensitivity analysis we observed similar estimates. The overall estimated proportion of chest CT inflammatory changes was $0.49(95 \% \mathrm{Cl} 0.39$ to 0.59 , $\mathrm{I}^{2}=93.6 \%$ ), whilst residual heterogeneity reduced to $71.0 \%$ after adjustment for timing of follow-up, explaining $9.3 \%$ of the variance. Prospective design and the severity of the cohort also contributed to variance in the estimate: $R^{2} 11.7 \%$ and $2.6 \%$, respectively (Supplementary Table 4). The overall estimated proportion of fibrotic changes was $0.34\left(95 \% \mathrm{Cl} 0.25\right.$ to $\left.0.43, \mathrm{I}^{2}=93.3 \%\right)$, adjustment for timing in meta regression reduced residual heterogeneity to $63.7 \%$, explaining $21.0 \%$ of variance, whilst risk of selection bias and approach to radiological classification also contributed to variance in the estimate: $R^{2} 21.1 \%$ and 2.9\%, respectively (Supplementary Table 5). The lowest unadjusted heterogeneity in estimate was observed at the 4-month follow-up, where inflammatory changes were estimated at a proportion of $0.53(95 \% \mathrm{Cl} 0.41$ to $\left.0.64, I^{2}=81.4 \%\right)$ whilst fibrotic changes were estimated at $0.32\left(95 \% \mathrm{Cl} 0.22\right.$ to $\left.0.43, I^{2}=84.9 \%\right)$ (Supplementary Figure 4). 
medRxiv preprint doi: https://doi.org/10.1101/2021.03.15.21253593; this version posted September 17, 2021. The copyright holder for this preprint (which was not certified by peer review) is the author/funder, who has granted medRxiv a license to display the preprint in perpetuity.

It is made available under a CC-BY-NC-ND 4.0 International license .

In sub analysis of studies that reported baseline outcomes, estimates of inflammatory changes were 0.92 (95\% Cl 0.87 to $\left.0.96, \mathrm{I}^{2}=89.4 \%\right)$ at baseline, $0.44\left(95 \% \mathrm{Cl} 0.35\right.$ to $\left.0.53, \mathrm{I}^{2}=89.3 \%\right)$ at follow-up, resulting in an estimated difference in proportion of $-0.47\left(-0.56\right.$ to $\left.-0.37, I^{2}=87.8 \%\right)$ over time (Figure 3). Estimates of fibrotic changes at baseline were $0.32\left(95 \% \mathrm{Cl} 0.15\right.$ to $\left.0.52, \mathrm{I}^{2}=98.0 \%\right)$ and $0.26(95 \% \mathrm{Cl} 0.17$ to 0.36 , $\left.\mathrm{I}^{2}=92.9 \%\right)$ at follow-up, with an estimated difference in proportion of $-0.09\left(95 \% \mathrm{Cl}-0.25\right.$ to $\left.0.07, \mathrm{I}^{2}=96.4 \%\right)$ over time (Figure 4). After adjustment for timing of follow-up, overall heterogeneity of estimates of inflammatory changes at matched follow up were reduced from $89.3 \%$ to $55.7 \%$, whilst heterogeneity in estimates of fibrotic changes at matched follow up were reduced from $92.9 \%$ to $58.3 \%$ (Supplementary Tables 4-5; Supplementary Figure 4). Prospective design contributed 5.3\% of variance in estimates of inflammatory changes, whilst selection bias explained $8.3 \%$ of variance in estimates of fibrotic changes.

In separate viral agent strata, the estimated proportion of patients with inflammatory changes during follow-up CT scans was 0.81 (95\%Cl 0.58 to $\left.0.97, \mathrm{I}^{2}=91.8 \%\right)$, and $0.61\left(95 \% \mathrm{Cl} 0.27\right.$ to $0.90, \mathrm{I}^{2}=93.3 \%$ ) following SARS-CoV and Influenza infections, respectively. The overall estimate of fibrotic changes during follow-up was $0.66\left(95 \% \mathrm{Cl} 0.43\right.$ to $0.86, \mathrm{I}^{2}=92.8 \%$ ), and $0.27\left(95 \% \mathrm{Cl} 0.15\right.$ to $0.40 . \mathrm{I}^{2}=57.1 \%$ ) following SARSCoV and Influenza infections, respectively (Supplementary Figure 5).

Lung function sequelae were described in a total of 64 papers, with 50 reaching sample size criteria for inclusion in quantitative synthesis. A total of 3146 tests for restrictive impairment and 3419 for impaired DLco were included following SARS-CoV-2 infection. Follow-up lung function tests were performed at a median of 3 months after discharge. The overall estimated proportion of individuals with impaired gas transfer during follow-up was $0.38\left(95 \% \mathrm{Cl} 0.32\right.$ to $\left.0.44 . \mathrm{I}^{2}=92.1 \%\right)$ and $0.38\left(95 \% \mathrm{Cl} 0.32\right.$ to $\left.0.44, \mathrm{I}^{2}=91.2 \%\right)$ in the restricted 3-6 months time frame (Figure 5; Supplementary Figure 6). In meta regression, adjustment for timing of follow-up reduced residual heterogeneity to $63.2 \%$ and $59.4 \%$ for impaired gas transfer overall and when restricted to 3-6 months window, respectively (Supplementary Table 6; Supplementary Figure 9). The overall estimated proportion of individuals with restrictive impairment within 12 months was 0.17 (95\% $\mathrm{Cl} 0.13$ to $\left.0.23 . \mathrm{I}^{2}=92.5 \%\right)$ and $0.14\left(95 \% \mathrm{Cl} 0.10\right.$ to $\left.0.19, \mathrm{I}^{2}=86.6 \%\right)$ when follow up was restricted to $3-$ 6 months (Figure 5; Supplementary Figure 7). In meta regression, adjustment for timing of follow-up 
reduced residual heterogeneity to $60.1 \%$ and $16.7 \%$ for restrictive impairment overall and when restricted to 3-6 months follow-up, respectively (Supplementary Table 7; Supplementary Figure 9). Severity of the cohort explained $35.5 \%$ of the variance in estimate in sensitivity analysis.

Estimates of the prevalence of restrictive impairment were similarly low across other viral pneumonias, $0.10\left(95 \% \mathrm{Cl} 0.05\right.$ to $\left.0.17, \mathrm{I}^{2}=80.2 \%\right)$ for SARS-CoV and in 6/73 participants with MERS-CoV (Supplementary Figure 7). Estimates of the prevalence of impaired gas transfer were similar in SARS-CoV compared to SARS-

CoV-2 (0.36; $95 \% \mathrm{Cl} 0.27$ to $\left.0.46, \mathrm{I}^{2}=84.4 \%\right)$, whilst prevalence was estimated to be higher following influenza $(0.54 ; 95 \% 110.43$ to 0.65$)$, and a single study of MERS-CoV identified gas transfer impairments in 25/73 participants.

Based on the GRADE framework, we have low confidence in estimates for all outcomes. All studies included in the quantitative synthesis had an observational design and moderate risk of bias as possible confounding factors were not extensively assessed and could not be modelled in estimates of proportion. Inconsistency between studies was considered moderate due to the substantial heterogeneity that could be reduced by adjustment for timing. No causes of indirectness were detected since all study subjects had confirmed viral pneumonia, although severity and eligibility criteria were inconsistent. We judged the risk of imprecision as moderate, due to the possible influence of sample size on proportion. Risk of publication bias evaluation identified symmetry and very low risk of bias in funnel plots (Supplementary Table 8; Supplementary Figures 10-11).

\section{Discussion}

We systematically investigated the prevalence of radiological and functional consequences posthospitalisation for viral pneumonitis, particularly for that caused by SARS-CoV-2. We observed the presence of inflammatory changes during hospitalisation in over $90 \%$ of CT scans, which reduced to $44 \%$ at a median follow up of 3 months. In contrast fibrotic changes were observed in a smaller percentage of CT scans (25-30\%), though estimates remained more consistent between hospitalisation and follow-up, suggesting persistent fibrotic change. In analyses of lung function, restrictive impairment was estimated in 
$15 \%$, whilst impaired gas transfer was observed in $39 \%$. Heterogeneity in overall estimates were frequently substantial and therefore results should be interpreted with caution. We demonstrate that parenchymal lung damage by viral insult may be common and has the potential to explain COVID-19 related breathlessness in the months following hospitalisation.

We observed that overall estimates of radiological findings were consistent in sensitivity analysis restricted to the 3-6 months follow up time points. Least heterogeneity without adjustment was observed at four months, suggesting similar timeframes may be suitable for radiological follow-up. The presence of chronic respiratory disease diagnoses prior to hospitalisation may lead to overestimation in the prevalence of radiological changes. We addressed this by performing a sub analysis on studies that report radiological findings during hospitalisation, which supports interpretation of changes over time although we cannot confirm exclusion of individuals with underlying respiratory conditions.

A high proportion of people with inflammatory findings such as ground glass opacities and consolidation were observed at baseline following SARS-CoV-2, consistent with the radiological signs commonly described for viral pneumonitis. ${ }^{118,119}$ The difference in inflammatory changes reduced over the course of matched follow-up. Fibrotic changes were observed in a similar proportion of people during hospitalisation and at follow-up, suggesting a potential lack of resolution in the first year following infection. Meta regression indicated that, whilst not always significant, estimates of radiological sequelae reduced over time, particularly for inflammatory changes and more slowly for fibrotic changes. Radiological and functional sequelae have been described up to five years after Influenza infections, ${ }^{15,114,120}$ and up to fifteen years after SARS-CoV. ${ }^{13,121,122}$

In individuals with SARS-CoV-2, restrictive and gas transfer impairment were associated with infection severity, ${ }^{40,42,43,63,70,123}$ with similar findings reported in SARS-CoV, 88,94 although not always statistically significant. ${ }^{42,124}$ We observe that the estimated prevalence of impaired gas transfer is greater than the prevalence of restrictive impairment following SARS-CoV-2 infection, with similar findings following other viral pneumonias. Meta-regression suggested that estimates of impaired gas transfer reduced over time, 
It is made available under a CC-BY-NC-ND 4.0 International license .

whilst the lower estimates of restrictive impairment did not change. Unresolved radiological changes and impaired lung function are important diagnostic tools for fibrotic interstitial lung disease, and prospective studies should accurately define the prevalence of post-COVID pulmonary fibrosis. ${ }^{125}$ (REF protocol when available)

Other systematic reviews have been published addressing radiological changes on CT and impairment to lung function in response to COVID-19, often limited to smaller numbers of studies, shorter follow-up, qualitative review alone, or lack of a preregistered protocol ${ }^{126-129}$ We included over 40 studies in quantitative synthesis of each radiological and physiological sequelae based on a preregistered protocol, including up to 12 months of follow-up, representing the largest systematic review and meta-analysis. High levels of heterogeneity are routinely reported in meta-analysis of proportions, so we perform sensitivity analysis, sub analysis and meta-regression to provide further reliable insights. We additionally model potential sources of heterogeneity in meta-regression, identifying timing of follow-up as an important characteristic to interpret estimates. A high risk of selection bias commonly contributed to variance in fibrotic estimates, whilst prospective design more commonly contributed to variance in inflammatory estimates, both of which highlight the impact of study inclusion criteria upon generalisability of systematic review findings. Unique to our protocol, we separately report estimates from Influenza and SARS-CoV studies, which suggest similar changes in response to non-COVID-19 viral pneumonitis.

There are limitations to this systematic review and meta-analysis. As our search strategy focused on followup tests, the number of included articles that reported baseline findings were limited, and no studies included CT findings prior to hospitalisation. Estimates of proportion are based on the number of tests performed, not patients infected, which would be affected by selection bias. Interpreting estimates requires caution as heterogeneity was frequently substantial and not completely attributable to the studylevel features evaluated, consistent reasons for outlying study estimates were not identified. It is likely that variability in case mix demographic and severity of acute infection contributed to the heterogeneity between studies, which may be addressed by individual patient data approaches. All estimates represent individuals hospitalised with infection, which may not reflect prevalence in non-hospitalised cases. We 
medRxiv preprint doi: https://doi.org/10.1101/2021.03.15.21253593; this version posted September 17, 2021. The copyright holder for this preprint (which was not certified by peer review) is the author/funder, who has granted medRxiv a license to display the preprint in perpetuity.

It is made available under a CC-BY-NC-ND 4.0 International license .

defined radiological sequelae attributable to inflammatory and fibrotic responses, however these were not always reported specifically or exclusively and there are limitations to classifying radiological patterns. Ground-glass opacities are not exclusive to inflammation and could reflect retractile fibrosis during follow up. Approach to radiological classification only explained minor variance in fibrotic estimates, specific patterning likely contributes to residual heterogeneity. Internationally standardised approaches to reporting of post-COVID radiological change would support patient management and epidemiological study.

We have demonstrated the presence of substantial radiological and functional sequelae following viral pneumonias that may be consistent with post-viral interstitial lung disease. These parenchymal sequelae of viral infection could have a considerable impact given the large numbers of people discharged from hospital with COVID-19. Whilst the certainty of the presented estimates is low, they justify vigilant radiological and functional follow up of individuals hospitalised with viral pneumonia. 


\section{Contributions}

IS had full access to all the data in the study and takes responsibility for the integrity of the data and the accuracy of the data analysis. LF, SM and IS have accessed and verified the underlying data. IS, GJ, AS and KR contributed to conceptualisation; IS, KR, JX, WC contributed to methodology; LF, SM, FK, WC contributed data curation; SM, FK, WC, JX contributed resource; LF, IS contributed formal analysis; IS, GJ contributed to supervision; GJ contributed funding acquisition; LF, IS contributed to writing - original draft. All authors contributed writing - review \& editing. LF, SM, FK, WC, JX, KR, AS and IS report no competing interests relating to the manuscript, GJ reports NIHR BRC salaries, studentships, professorship (RP-2017-08ST2-014). GJ also reports consulting fees and honoraria from Biogen, Galapagos, Galecto, GlaxoSmithKline, Heptares, MedImmuine, Pliant, PharmAkea, Bristol Myers Squibb, Veracyte, Boehringer Ingelheim, NordicBiosciences, Roche, Chiesi. The funder of the study (NIHR) had no role in study design, data collection, data analysis, data interpretation, or writing of the report. We acknowledge the following individuals for their correspondence and support in extracting individual study data: Dr Alexandra Kadl, Dr Ayham Daher, Dr Chris Ryerson, Dr David Arnold, Dr Edita Strumiliene, Dr Ernesto Crisafulli, Dr Fabio Anastasio, Dr Francesco Lombardi, Dr Gianluca Boari, Dr Giovanni Barisione, Dr Hosein Tabatabaei, Dr Jiang Yongpo, Dr Jose Alberto Fernandez Villar, Dr Li He, Dr Marco Marando, Dr Mattia Bellan, Dr Michiel de Graaf, Dr Mostafa Rasha, Dr Nick Maskell, Dr Rob van Gassel, Dr Susanne van Santen, Dr William Man. 


\section{References}

1. WHO. General's opening remarks at the media briefing on COVID-19 2020.

2. WHO. Coronavirus Disease (COVID-19). https://covid19.who.int/.

3. Guan W-j, Ni Z-y, Hu Y, et al. Clinical Characteristics of Coronavirus Disease 2019 in China. N Engl J Med. 2020;382(18):1708-1720.

4. Arnold DT, Hamilton FW, Milne A, et al. Patient outcomes after hospitalisation with COVID-19 and implications for follow-up: results from a prospective UK cohort. Thorax. 2020:thoraxjnl-2020216086.

5. Carfi A, Bernabei R, Landi F, Gemelli Against C-P-ACSG. Persistent Symptoms in Patients After Acute COVID-19. Jama. 2020;324(6):603-605.

6. Mandal S, Barnett J, Brill SE, et al. 'Long-COVID': a cross-sectional study of persisting symptoms, biomarker and imaging abnormalities following hospitalisation for COVID-19. Thorax. 2020.

7. Carsana L, Sonzogni A, Nasr A, et al. Pulmonary post-mortem findings in a series of COVID-19 cases from northern Italy: a two-centre descriptive study. The Lancet Infectious Diseases. 2020;20(10):1135-1140.

8. Ducloyer M, Gaborit B, Toquet C, et al. Complete post-mortem data in a fatal case of COVID-19: clinical, radiological and pathological correlations. Int J Legal Med. 2020;134(6):2209-2214.

9. Zhao L, Wang X, Xiong Y, Fan Y, Zhou Y, Zhu W. Correlation of autopsy pathological findings and imaging features from 9 fatal cases of COVID-19 pneumonia. Medicine (Baltimore). 2021;100(12):e25232.

10. Jenkins G. Demystifying pulmonary fibrosis. Am J Physiol Lung Cell Mol Physiol. 2020;319(3):L554L559.

11. Jolly L, Stavrou A, Vanderstoken G, et al. Influenza promotes collagen deposition via alphavbeta6 integrin-mediated transforming growth factor beta activation. J Biol Chem. 2014;289(51):3524635263.

12. Das KM, Lee EY, Singh R, et al. Follow-up chest radiographic findings in patients with MERS-CoV after recovery. Indian J Radiol Imaging. 2017;27(3):342-349.

13. Wu X, Dong D, Ma D. Thin-Section Computed Tomography Manifestations During Convalescence and Long-Term Follow-Up of Patients with Severe Acute Respiratory Syndrome (SARS). Med Sci Monit. 2016;22:2793-2799.

14. Xie L, Liu Y, Fan B, et al. Dynamic changes of serum SARS-coronavirus IgG, pulmonary function and radiography in patients recovering from SARS after hospital discharge. Respir Res. 2005;6:5.

15. Xing ZH, Sun $X, X u L$, et al. Thin-section computed tomography detects long-term pulmonary sequelae 3 years after novel influenza A virus-associated pneumonia. Chin Med J (Engl). 2015;128(7):902-908.

16. Qiao J, Zhang M, Bi J, et al. Pulmonary fibrosis induced by H5N1 viral infection in mice. Respir Res. 2009;10(1):107.

17. Plantier L, Cazes A, Dinh-Xuan AT, Bancal C, Marchand-Adam S, Crestani B. Physiology of the lung in idiopathic pulmonary fibrosis. Eur Respir Rev. 2018;27(147).

18. Raghu G, Remy-Jardin M, Myers JL, et al. Diagnosis of Idiopathic Pulmonary Fibrosis. An Official ATS/ERS/JRS/ALAT Clinical Practice Guideline. American Journal of Respiratory and Critical Care Medicine. 2018;198(5):e44-e68.

19. Liberati A, Altman DG, Tetzlaff J, et al. The PRISMA statement for reporting systematic reviews and meta-analyses of studies that evaluate healthcare interventions: explanation and elaboration. Bmj. 2009;339:b2700.

20. da Costa Santos CM, de Mattos Pimenta CA, Nobre MR. The PICO strategy for the research question construction and evidence search. Rev Lat Am Enfermagem. 2007;15(3):508-511.

21. Nyaga VN, Arbyn M, Aerts M. Metaprop: a Stata command to perform meta-analysis of binomial data. Archives of Public Health. 2014;72(1):39. 
22. CLARITY Group. https://www.evidencepartners.com/resources/methodological-resources/.

23. Barisione $G$, Brusasco V. Lung diffusing capacity for nitric oxide and carbon monoxide following mild-to-severe COVID-19. Physiol Rep. 2021;9(4):e14748.

24. Granholm A, Alhazzani W, Møller MH. Use of the GRADE approach in systematic reviews and guidelines. Br J Anaesth. 2019;123(5):554-559.

25. Anastasio F, Barbuto S, Scarnecchia E, et al. Medium-term impact of COVID-19 on pulmonary function, functional capacity and quality of life. Eur Respir J. 2021;11.

26. Bellan M, Soddu D, Balbo PE, et al. Respiratory and Psychophysical Sequelae Among Patients With COVID-19 Four Months After Hospital Discharge. JAMA Netw Open. 2021;4(1):e2036142.

27. Boari GEM, Bonetti S, Braglia-Orlandini F, et al. Short-Term Consequences of SARS-CoV-2-Related Pneumonia: A Follow Up Study. High Blood Press Cardiovasc Prev. 2021.

28. Bonnesen B, Toennesen LL, Rasmussen KB, et al. Early improvements in pulmonary function after severe COVID-19 requiring mechanical ventilation. Infectious Diseases. 2021;53(3):218-221.

29. Cao J, Zheng X, Wei W, et al. Three-month outcomes of recovered COVID-19 patients: prospective observational study. Ther Adv Respir Dis. 2021;15(no pagination):17534666211009410.

30. Crisafulli E, Gabbiani D, Magnani G, et al. Residual lung function impairment is associated with hyperventilation in patients recovered from hospitalised covid-19: A cross-sectional study. Journal of Clinical Medicine. 2021;10(5):1-6.

31. Daher A, Balfanz P, Cornelissen C, et al. Follow up of patients with severe coronavirus disease 2019 (COVID-19): Pulmonary and extrapulmonary disease sequelae. Respir Med. 2020;174:106197.

32. de Graaf MA, Antoni ML, Ter Kuile MM, et al. Short-term outpatient follow-up of COVID-19 patients: A multidisciplinary approach. EClinicalMedicine. 2021;32:100731.

33. Ekbom E, Frithiof $R$, Emilsson $O$, et al. Impaired diffusing capacity for carbon monoxide is common in critically ill Covid-19 patients at four months post-discharge. Respir Med. 2021;182:106394.

34. Finney LJ, Doughty R, Lovage S, et al. Lung Function Deficits and Symptom Burden in Survivors of COVID-19 Requiring Mechanical Ventilation. Ann Am Thorac Soc. 2021;26.

35. Frija-Masson J, Debray MP, Boussouar S, et al. Residual ground glass opacities three months after Covid-19 pneumonia correlate to alteration of respiratory function: The post Covid M3 study. Respir Med. 2021;184:106435.

36. Froidure A, Mahsouli A, Liistro G, et al. Integrative respiratory follow-up of severe COVID-19 reveals common functional and lung imaging sequelae. Respir Med. 2021;181:106383.

37. Gianella P, Rigamonti E, Marando M, et al. Clinical, radiological and functional outcomes in patients with SARS-CoV-2 pneumonia: a prospective observational study. BMC polm. 2021;21(1):136.

38. Gonzalez J, Benitez ID, Carmona P, et al. Pulmonary Function and Radiologic Features in Survivors of Critical COVID-19: A 3-Month Prospective Cohort. Chest. 2021;04.

39. Gulati A, Lakhani P. Interstitial lung abnormalities and pulmonary fibrosis in COVID-19 patients: a short-term follow-up case series. Clinical Imaging. 2021;77:180-186.

40. Guler SA, Ebner L, Beigelman C, et al. Pulmonary function and radiological features four months after COVID-19: first results from the national prospective observational Swiss COVID-19 lung study. Eur Respir J. 2021:2003690.

41. Han X, Fan Y, Alwalid O, et al. Six-Month Follow-up Chest CT findings after Severe COVID-19 Pneumonia. Radiology. 2021:203153.

42. Huang C, Huang L, Wang Y, et al. 6-month consequences of COVID-19 in patients discharged from hospital: a cohort study. Lancet. 2021;397(10270):220-232.

43. Huang Y, Tan C, Wu J, et al. Impact of coronavirus disease 2019 on pulmonary function in early convalescence phase. Respir Res. 2020;21(1):163.

44. Labarca G, Henriquez-Beltran M, Lastra J, et al. Analysis of clinical symptoms, radiological changes and pulmonary function data 4 months after COVID-19. Clin Respir J. 2021;04.

45. Lago VC, Prudente RA, Luzia DA, et al. Persistent interstitial lung abnormalities in post-COVID-19 patients: a case series. J Venom Anim Toxins Incl Trop Dis. 2021;27:e20200157.

46. Lerum TV, Aaløkken TM, Brønstad E, et al. Dyspnoea, lung function and CT findings 3 months after hospital admission for COVID-19. Eur Respir J. 2021;57(4):2003448. 
47. Li R, Liu G, Huang X, et al. Dynamic changes in clinical and CT characteristics of COVID-19 cases with different exposure histories: a retrospective study. BMC Infect Dis. 2020;20(1):567.

48. Li X, Shen C, Wang L, et al. Pulmonary fibrosis and its related factors in discharged patients with new corona virus pneumonia: a cohort study. Respir Res. 2021;22(1).

49. Liang L, Yang B, Jiang N, et al. Three-month Follow-up Study of Survivors of Coronavirus Disease 2019 after Discharge. J Korean Med Sci. 2020;35(47):e418.

50. Liu C, Ye L, Xia R, et al. Chest Computed Tomography and Clinical Follow-Up of Discharged Patients with COVID-19 in Wenzhou City, Zhejiang, China. Ann Am Thorac Soc. 2020;17(10):1231-1237.

51. Liu D, Zhang W, Pan F, et al. The pulmonary sequalae in discharged patients with COVID-19: a shortterm observational study. Respir Res. 2020;21(1):125.

52. Liu M, Lv F, Huang Y, Xiao K. Follow-Up Study of the Chest CT Characteristics of COVID-19 Survivors Seven Months After Recovery. Front Med (Lausanne). 2021;8:636298.

53. Liu X, Zhou H, Zhou Y, et al. Temporal radiographic changes in COVID-19 patients: relationship to disease severity and viral clearance. Sci Rep. 2020;10(1):10263.

54. Lombardi F, Calabrese A, lovene B, et al. Residual respiratory impairment after COVID-19 pneumonia. BMC polm. 2021;21(1):241.

55. Lv D, Chen X, Wang X, et al. Pulmonary function of patients with 2019 novel coronavirus inducedpneumonia: a retrospective cohort study. Ann Palliat Med. 2020;9(5):3447-3452.

56. McGroder CF, Zhang D, Choudhury MA, et al. Pulmonary fibrosis 4 months after COVID-19 is associated with severity of illness and blood leucocyte telomere length. Thorax. 2021;203(9).

57. Miwa M, Nakajima M, Kaszynski RH, et al. Abnormal pulmonary function and imaging studies in critical COVID-19 survivors at 100 days after the onset of symptoms. Respiratory Investigation. 2021.

58. Morin L, Savale L, Pham T, et al. Four-Month Clinical Status of a Cohort of Patients after Hospitalization for COVID-19. JAMA - Journal of the American Medical Association. 2021;325(15):1525-1534.

59. Myall KJ, Mukherjee B, Castanheira AM, et al. Persistent Post-COVID-19 Inflammatory Interstitial Lung Disease: An Observational Study of Corticosteroid Treatment. Ann Am Thorac Soc. 2021.

60. Noel-Savina E, Viatge T, Faviez G, et al. Severe SARS-CoV-2 pneumonia: Clinical, functional and imaging outcomes at 4 months. Respiratory Medicine and Research. 2021;80 (no pagination).

61. Nunez-Fernandez M, Ramos-Hernandez C, Garcia-Rio F, et al. Alterations in Respiratory Function Test Three Months after Hospitalisation for COVID-19 Pneumonia: Value of Determining Nitric Oxide Diffusion. J Clin Med. 2021;10(10).

62. Polese J, Sant'Ana L, Moulaz IR, et al. Pulmonary function evaluation after hospital discharge of patients with severe COVID-19. Clinics. 2021;76:e2848.

63. Qin W, Chen S, Zhang Y, et al. Diffusion Capacity Abnormalities for Carbon Monoxide in Patients with COVID-19 At Three-Month Follow-up. The European respiratory journal. 2021;11.

64. Raman B, Cassar MP, Tunnicliffe EM, et al. Medium-term effects of SARS-CoV-2 infection on multiple vital organs, exercise capacity, cognition, quality of life and mental health, post-hospital discharge. EClinicalMedicine. 2021;31:100683.

65. Ramani C, Davis EM, Kim JS, Provencio JJ, Enfield KB, Kadl A. Post-ICU COVID-19 Outcomes: A Case Series. Chest. 2021;159(1):215-218.

66. Santus P, Flor N, Saad M, et al. Trends over Time of Lung Function and Radiological Abnormalities in COVID-19 Pneumonia: A Prospective, Observational, Cohort Study. J Clin Med. 2021;10(5):1-17.

67. Schandl A, Hedman A, Lynga P, et al. Long-term consequences in critically ill COVID-19 patients: A prospective cohort study. Acta Anaesthesiol Scand. 2021;07.

68. Shah AS, Wong AW, Hague CJ, et al. A prospective study of 12 -week respiratory outcomes in COVID-19-related hospitalisations. Thorax. 2020:thoraxjnl-2020-216308.

69. Sibila O, Albacar N, Perea L, et al. Lung Function sequelae in COVID-19 Patients 3 Months After Hospital Discharge. Arch Bronconeumol. 2021;57 Suppl 2(Supplement 2):59-61.

70. Smet J, Stylemans D, Hanon S, Ilsen B, Verbanck S, Vanderhelst E. Clinical status and lung function 10 weeks after severe SARS-CoV-2 infection. Respir Med. 2021;176:106276. 
71. Strumiliene E, Zeleckiene I, Bliudzius R, et al. Follow-Up Analysis of Pulmonary Function, Exercise Capacity, Radiological Changes, and Quality of Life Two Months after Recovery from SARS-CoV-2 Pneumonia. Medicina (B Aires). 2021;57(6):03.

72. Tabatabaei SMH, Rajebi H, Moghaddas F, Ghasemiadl M, Talari H. Chest CT in COVID-19 pneumonia: what are the findings in mid-term follow-up? Emerg Radiol. 2020;27(6):711-719.

73. van der Sar-van der Brugge S, Talman S, Boonman-de Winter L, et al. Pulmonary function and health-related quality of life after COVID-19 pneumonia. Respir Med. 2021;176:106272.

74. van Gassel RJJ, Bels J, Remij L, et al. Functional Outcomes and Their Association With Physical Performance in Mechanically Ventilated Coronavirus Disease 2019 Survivors at 3 Months Following Hospital Discharge: A Cohort Study. Crit Care Med. 2021;10.

75. van Gassel RJJ, Bels JLM, Raafs A, et al. High Prevalence of Pulmonary Sequelae at 3 Months after Hospital Discharge in Mechanically Ventilated Survivors of COVID-19. Am J Respir Crit Care Med. 2021;203(3):371-374.

76. Wei J, Yang H, Lei P, et al. Analysis of thin-section CT in patients with coronavirus disease (COVID19) after hospital discharge. J Xray Sci Technol. 2020;28(3):383-389.

77. Wu Q, Zhong L, Li H, et al. A Follow-Up Study of Lung Function and Chest Computed Tomography at 6 Months after Discharge in Patients with Coronavirus Disease 2019. Can Respir J. 2021;2021:6692409.

78. Wu X, Liu X, Zhou Y, et al. 3-month, 6-month, 9-month, and 12-month respiratory outcomes in patients following COVID-19-related hospitalisation: a prospective study. Lancet Respir Med. 2021;05.

79. Yasin R, Gomaa AAK, Ghazy T, Hassanein SA, Ibrahem RAl, Khalifa MH. Predicting lung fibrosis in post-COVID-19 patients after discharge with follow-up chest CT findings. Egyptian Journal of Radiology and Nuclear Medicine. 2021;52(1).

80. Yu M, Liu Y, Xu D, Zhang R, Lan L, Xu H. Prediction of the Development of Pulmonary Fibrosis Using Serial Thin-Section CT and Clinical Features in Patients Discharged after Treatment for COVID-19 Pneumonia. Korean J Radiol. 2020;21(6):746-755.

81. Zhang S, Bai W, Yue J, et al. Eight months follow-up study on pulmonary function, lung radiographic, and related physiological characteristics in COVID-19 survivors. Sci. 2021;11(1):13854.

82. Zhao YM, Shang YM, Song WB, et al. Follow-up study of the pulmonary function and related physiological characteristics of COVID-19 survivors three months after recovery. EClinicalMedicine. 2020;25:100463.

83. Zhong L, Zhang S, Wang J, et al. Analysis of Chest CT Results of Coronavirus Disease 2019 (COVID19) Patients at First Follow-Up. Can Respir J. 2020;2020:5328267.

84. Antonio GE, Wong KT, Hui DS, et al. Thin-section CT in patients with severe acute respiratory syndrome following hospital discharge: preliminary experience. Radiology. 2003;228(3):810-815.

85. Jin ZY, You $\mathrm{H}$, Zhang WH, et al. [Thoracic high resolution CT findings of 100 SARS patients in convalescent period]. Zhongguo Yi Xue Ke Xue Yuan Xue Bao. 2003;25(5):512-515.

86. Liu T, Peng M, Cai BQ, et al. [Assessment of health-related quality of life in cured SARS patients]. Zhongguo Yi Xue Ke Xue Yuan Xue Bao. 2003;25(5):516-519.

87. Peng $\mathrm{M}, \mathrm{Cai} \mathrm{BQ}$, Liu $\mathrm{T}$, et al. [Assessment of pulmonary function in SARS patients during the convalescent period]. Zhongguo Yi Xue Ke Xue Yuan Xue Bao. 2003;25(5):529-532.

88. Chiang CH, Shih JF, Su WJ, Perng RP. Eight-month prospective study of 14 patients with hospitalacquired severe acute respiratory syndrome. Mayo Clin Proc. 2004;79(11):1372-1379.

89. Hsu HH, Tzao C, Wu CP, et al. Correlation of high-resolution CT, symptoms, and pulmonary function in patients during recovery from severe acute respiratory syndrome. Chest. 2004;126(1):149-158.

90. Ng CK, Chan JW, Kwan TL, et al. Six month radiological and physiological outcomes in severe acute respiratory syndrome (SARS) survivors. Thorax. 2004;59(10):889-891.

91. Wong KT, Antonio GE, Hui DS, et al. Severe acute respiratory syndrome: thin-section computed tomography features, temporal changes, and clinicoradiologic correlation during the convalescent period. J Comput Assist Tomogr. 2004;28(6):790-795. 
It is made available under a CC-BY-NC-ND 4.0 International license .

92. Beijing Respiratory Experts Panel of the Medical Staff Severe Acute Respiratory Syndrome P. [A follow-up study of the lung function and the chest CT changes in medical staff with severe acute respiratory syndrome in Beijing]. Zhonghua Jie He He Hu Xi Za Zhi. 2005;28(1):10-12.

93. Chang YC, Yu CJ, Chang SC, et al. Pulmonary sequelae in convalescent patients after severe acute respiratory syndrome: evaluation with thin-section CT. Radiology. 2005;236(3):1067-1075.

94. Hui DS, Wong KT, Ko FW, et al. The 1-year impact of severe acute respiratory syndrome on pulmonary function, exercise capacity, and quality of life in a cohort of survivors. Chest. 2005;128(4):2247-2261.

95. Ong KC, Ng AW, Lee LS, et al. 1-year pulmonary function and health status in survivors of severe acute respiratory syndrome. Chest. 2005;128(3):1393-1400.

96. Zheng ZG, Chen RC, Wu H, et al. [Changes in pulmonary function in severe acute respiratory syndrome patients during convalescent period]. Zhongguo Wei Zhong Bing Ji Jiu Yi Xue. 2005;17(6):329-331.

97. Chen X, Lin J, Yu H. Research of pulmonary function, health-related quality of life of cured patients with severe acute respiratory syndrome and the effect of Chinese traditional medicine treatment during recovery. [Chinese]. Chinese Journal of Rehabilitation Medicine. 2006;21(2):124-126.

98. Li TS, Gomersall CD, Joynt GM, Chan DP, Leung P, Hui DS. Long-term outcome of acute respiratory distress syndrome caused by severe acute respiratory syndrome (SARS): an observational study. Crit Care Resusc. 2006;8(4):302-308.

99. Tansey CM, Louie M, Loeb M, et al. One-year outcomes and health care utilization in survivors of severe acute respiratory syndrome. Arch Intern Med. 2007;167(12):1312-1320.

100. Xie L, Liu Y, Xiao Y, et al. Follow-up study on pulmonary function and lung radiographic changes in rehabilitating severe acute respiratory syndrome patients after discharge. Chest. 2005;127(6):21192124.

101. Park WB, Jun KI, Kim G, et al. Correlation between Pneumonia Severity and Pulmonary Complications in Middle East Respiratory Syndrome. J Korean Med Sci. 2018;33(24):e169.

102. Bai L, Gu L, Cao B, et al. Clinical features of pneumonia caused by 2009 influenza A(H1N1) virus in Beijing, China. Chest. 2011;139(5):1156-1164.

103. Chen J, Wu J, Hao S, et al. Long term outcomes in survivors of epidemic Influenza A (H7N9) virus infection. Sci Rep. 2017;7(1):17275.

104. Dai J, Zhou X, Dong D, et al. Human infection with a novel avian-origin influenza A (H7N9) virus: serial chest radiographic and CT findings. Chin Med J (Engl). 2014;127(12):2206-2211.

105. Edgeworth D, Brohan J, O'Neill S, Maher M, Breen D, Murphy D. Pulmonary sequelae of severe H1N1 infection treated with high frequency oscillatory ventilation. Ir Med J. 2013;106(8):249-252.

106. Hsieh MJ, Lee WC, Cho HY, et al. Recovery of pulmonary functions, exercise capacity, and quality of life after pulmonary rehabilitation in survivors of ARDS due to severe influenza A (H1N1) pneumonitis. Influenza Other Respir Viruses. 2018;12(5):643-648.

107. Li H, Weng H, Lan C, et al. Comparison of patients with avian influenza A (H7N9) and influenza A (H1N1) complicated by acute respiratory distress syndrome. Medicine (Baltimore). 2018;97(12):e0194.

108. Liu W, Peng L, Liu H, Hua S. Pulmonary Function and Clinical Manifestations of Patients Infected with Mild Influenza A Virus Subtype H1N1: A One-Year Follow-Up. PLoS ONE. 2015;10(7):e0133698.

109. Lu PX, Wang YX, Zhou BP, et al. Radiological features of lung changes caused by avian influenza subtype A H5N1 virus: report of two severe adult cases with regular follow-up. Chin Med J (Engl). 2010;123(1):100-104.

110. Luyt CE, Combes A, Becquemin MH, et al. Long-term outcomes of pandemic 2009 influenza A(H1N1)-associated severe ARDS. Chest. 2012;142(3):583-592.

111. Mineo G, Ciccarese F, Modolon C, Landini MP, Valentino M, Zompatori M. Post-ARDS pulmonary fibrosis in patients with H1N1 pneumonia: role of follow-up CT. Radiol Med. 2012;117(2):185-200.

112. Quispe-Laime AM, Fiore C, Gonzalez-Ros MN, et al. [Lung diffusion capacity and quality of life 6 months after discharge from the ICU among survivors of acute respiratory distress syndrome due to influenza A H1N1]. Med Intensiva. 2012;36(1):15-23. 
113. Saha A, Vaidya PJ, Chavhan VB, Achlerkar A, Leuppi JD, Chhajed PN. Combined pirfenidone, azithromycin and prednisolone in post-H1N1 ARDS pulmonary fibrosis. Sarcoidosis Vasc Diffuse Lung Dis. 2018;35(1):85-90.

114. Singh V, Sharma BB, Patel V. Pulmonary sequelae in a patient recovered from swine flu. Lung India. 2012;29(3):277-279.

115. Toufen C, Jr., Costa EL, Hirota AS, Li HY, Amato MB, Carvalho CR. Follow-up after acute respiratory distress syndrome caused by influenza a (H1N1) virus infection. Clinics (Sao Paulo). 2011;66(6):933937.

116. Winterbauer RH, Ludwig WR, Hammar SP. Clinical course, management, and long-term sequelae of respiratory failure due to influenza viral pneumonia. Johns Hopkins Med J. 1977;141(3):148-155.

117. Zarogoulidis $\mathrm{P}$, Kouliatsis $\mathrm{G}$, Papanas $\mathrm{N}$, et al. Long-term respiratory follow-up of H1N1 infection. Virol J. 2011;8:319.

118. Franquet T. Imaging of pulmonary viral pneumonia. Radiology. 2011;260(1):18-39.

119. Koo HJ, Choi SH, Sung H, Choe J, Do KH. RadioGraphics Update: Radiographic and CT Features of Viral Pneumonia. Radiographics. 2020;40(4):E8-E15.

120. Wang $\mathrm{Q}$, Jiang $\mathrm{H}$, Xie $\mathrm{Y}$, et al. Long-term clinical prognosis of human infections with avian influenza $\mathrm{A}(\mathrm{H} 7 \mathrm{N9})$ viruses in China after hospitalization. EClinicalMedicine. 2020;20:100282.

121. Guo L, Han Y, Li J, et al. Long-term outcomes in patients with severe acute respiratory syndrome treated with oseltamivir: A 12-year longitudinal study. International Journal of Clinical and Experimental Medicine. 2019;12(10):12464-12471.

122. Zhang P, Li J, Han N, et al. Long-term consequences in lung and bone associated with hospitalacquired severe acute respiratory syndrome: a 15-year follow-up from a prospective cohort study. The Lancet. 2018;392 (Supplement 1):S11.

123. Mo X, Jian W, Su Z, et al. Abnormal pulmonary function in COVID-19 patients at time of hospital discharge. Eur Respir J. 2020;55(6):2001217.

124. Faverio P, Luppi F, Rebora P, et al. Six-Month Pulmonary Impairment after Severe COVID-19: A Prospective, Multicentre Follow-Up Study. Respiration. 2021.

125. Understanding the burden of Interstitial Lung Disease post-COVID19: The UK Interstitial Lung Disease Post-COVID Study (UKILD-Post COVID). 2021; https://www.imperial.ac.uk/news/218933/new-national-study-long-term-impacts-lung/.

126. Ojha V, Mani A, Pandey NN, Sharma S, Kumar S. CT in coronavirus disease 2019 (COVID-19): a systematic review of chest $\mathrm{CT}$ findings in 4410 adult patients. European Radiology. 2020;30(11):6129-6138.

127. Polak SB, Van Gool IC, Cohen D, von der Thüsen JH, van Paassen J. A systematic review of pathological findings in COVID-19: a pathophysiological timeline and possible mechanisms of disease progression. Modern Pathology. 2020;33(11):2128-2138.

128. So M, Kabata H, Fukunaga K, Takagi H, Kuno T. Radiological and functional lung sequelae of COVID19: a systematic review and meta-analysis. BMC polm. 2021;21(1):97.

129. Torres-Castro R, Vasconcello-Castillo L, Alsina-Restoy $X$, et al. Respiratory function in patients postinfection by COVID-19: a systematic review and meta-analysis. Pulmonology. 2021;27(4):328-337. 


\section{Figure legends:}

Figure 1: Systematic search and screening strategy. Flow diagram illustrates systematic search and screening strategy, including numbers meeting eligibility criteria and numbers excluded. Searches updated on the $29^{\text {th }}$ of July 2021.

\section{Figure 2. Radiological findings at follow-up in SARS-CoV-2 studies}

Estimates are reported as proportion of number of CT scans showing the outcome of interest $(n)$ on the total number of exams performed $(\mathrm{N}$ ) and $95 \%$ confidence interval. Inflammatory radiological findings were defined as ground-glass opacification or consolidation. Fibrotic radiological findings were defined as either reticulation, lung architectural distortion, interlobular septal thickening, traction bronchiectasis, or honeycombing.

Figure 3. Inflammatory findings at baseline and matched follow-up in SARS-CoV-2 studies: sub analysis

Estimates are reported as proportion of number of CT scans showing the outcome of interest $(n)$ on the total number of exams performed $(\mathrm{N})$ and $95 \%$ confidence interval. Baseline defined as during hospitalisation, follow-up defined as post discharge. Inflammatory radiological findings were defined as ground-glass opacification or consolidation.

Figure 4. Radiological fibrotic findings at baseline and matched follow-up in SARS-CoV-2 studies: sub analysis

Estimates are reported as proportion of number of CT scans showing the outcome of interest $(n)$ on the total number of exams performed $(\mathrm{N})$ and $95 \%$ confidence interval. Baseline defined as during hospitalisation, follow-up defined as post discharge. Fibrotic radiological findings were defined as either reticulation, lung architectural distortion, interlobular septal thickening, traction bronchiectasis, or honeycombing.

\section{Figure 5. Pulmonary function testing at follow-up}

Estimates are reported as proportion of number of tests showing the outcome of interest $(n)$ on the total number of exams performed $(\mathrm{N})$ and $95 \%$ confidence interval. Restrictive lung impairment was defined as a total lung capacity (TLC) $<80 \%$ predicted value or forced vital capacity $(\mathrm{FVC})<80 \%$ predicted value with normal-to-high FEV1/FVC ratio. Impaired gas transfer was defined as percent predicted DLCO $<80 \%$. 
medRxiv preprint doi: https://doi.org/10.1101/2021.03.15.21253593; this version posted September 17, 2021. The copyright holder for this preprint (which was not certified by peer review) is the author/funder, who has granted medRxiv a license to display the preprint in perpetuity.

It is made available under a CC-BY-NC-ND 4.0 International license .

Table 1. SARS-CoV-2 Studies overview

\begin{tabular}{|c|c|c|c|c|c|c|c|c|}
\hline Author(s) & Year & Study design & Sample size & Age Reporting (years) & FU & Severity & $\begin{array}{l}\text { Selection } \\
\text { bias }\end{array}$ & $\begin{array}{l}\text { Quantitative } \\
\text { synthesis }\end{array}$ \\
\hline Anastasio et.al $^{25}$ & 2021 & P Cohort & 222 & median+IQR 58(53-67) & 4 & 1 & 0 & $d, r$ \\
\hline Arnold et al. ${ }^{4}$ & 2020 & P Cohort & 110 & $\begin{array}{c}\text { median+IOR } 60 \text { (46- } \\
73 \text { ) } \\
\end{array}$ & 3 & 1 & 0 & $r$ \\
\hline Barisione et al. $^{23}$ & 2021 & P Cohort & 94 & mean+SD 61(12.1) & 1 & 1 & 0 & $\mathrm{i}, \mathrm{f}, \mathrm{d}$ \\
\hline Bellan et al. ${ }^{26}$ & 2021 & P Cohort & 238 & $\begin{array}{c}\text { median+IQR } 61 \text { (50- } \\
71)\end{array}$ & 4 & 1 & 1 & $d, r$ \\
\hline Boari et al. $^{27}$ & 2021 & P Cohort & 94 & mean+SD 66(11) & 4 & 1 & 1 & $f, d$ \\
\hline Bonnesen et al. ${ }^{28}$ & 2021 & P Cohort & 12 & median+IQR 62(57-67) & 3 & 2 & 1 & \\
\hline Cao et al. ${ }^{29}$ & 2021 & P Cohort & 81 & mean+SD 45(15) & 3 & 1 & 0 & $\mathrm{i}, \mathrm{f}, \mathrm{r}$ \\
\hline Crisafulli et al. ${ }^{30}$ & 2021 & P Cohort & 81 & mean+SD 66.5(11.2) & 4 & 1 & 0 & $d, r$ \\
\hline Daher et al. ${ }^{31}$ & 2020 & P Cohort & 33 & mean+SD 64 (3) & 1.5 & 0 & 0 & $d, r$ \\
\hline de Graaf et al. ${ }^{32}$ & 2021 & P Cohort & 81 & mean+SD $61(13)$ & 1.5 & 1 & 1 & - \\
\hline Ekbom et al. ${ }^{33}$ & 2021 & P Cohort & 60 & mean+range 59(27-82) & 4 & 2 & 1 & $d, r$ \\
\hline Finney at al. ${ }^{34}$ & 2021 & P Cohort & 50 & $\begin{array}{c}\text { median+IQR 54.5(44- } \\
59)\end{array}$ & 1.5 & 2 & 1 & - \\
\hline Frija-Masson et al. $^{35}$ & 2021 & P Cohort & 137 & median+IQR 59(50-68) & 3 & 1 & 1 & $i, f, d, r$ \\
\hline Froidure et al. ${ }^{36}$ & 2021 & P Cohort & 134 & median+IQR 60(53-68) & 3 & 2 & 0 & $\mathrm{i}, \mathrm{f}, \mathrm{d}, \mathrm{r}$ \\
\hline Gianella et al. ${ }^{37}$ & 2021 & P Cohort & 39 & \begin{tabular}{|c|} 
median+IQR 62.5 (51- \\
$71)$
\end{tabular} & 3 & 1 & 0 & $i, f, d, r$ \\
\hline Gonzalez et al. ${ }^{38}$ & 2021 & P Cohort & 62 & $\begin{array}{c}\text { median+IQR } 60 \text { (48- } \\
65)\end{array}$ & 3 & 2 & 1 & $i, f, d, r$ \\
\hline Gulati et al..$^{39}$ & 2021 & R Case series & 12 & $\begin{array}{c}\text { mean+range } 65.1(35- \\
89)\end{array}$ & 3 & 1 & 1 & - \\
\hline Guler et al. ${ }^{40}$ & 2021 & P Cohort & 113 & $\begin{array}{c}\text { mean+SD } 57.22 \\
(12.11)\end{array}$ & 4 & 1 & 0 & $\mathrm{i}, \mathrm{f}$ \\
\hline Han et al. ${ }^{41}$ & 2021 & P Cohort & 114 & mean+SD 54 (12) & 6 & 2 & 1 & $\mathrm{i}, \mathrm{f}, \mathrm{d}$ \\
\hline Huang C., et al. ${ }^{42}$ & 2021 & P Cohort & 1733 & $\begin{array}{c}\text { median+IQR } 57 \text { (47- } \\
65)\end{array}$ & 6 & 1 & 1 & $i, f, d, r$ \\
\hline Huang, Y., et al. ${ }^{43}$ & 2020 & $\begin{array}{l}\text { P Cross- } \\
\text { Sectional }\end{array}$ & 57 & $\begin{array}{c}\text { mean+SD } 46.72 \\
(13.78) \\
\end{array}$ & 1 & 1 & 1 & $f, d, r$ \\
\hline Labarca et al. ${ }^{44}$ & 2021 & $\begin{array}{l}\text { P Cross- } \\
\text { Sectional }\end{array}$ & 42 & mean+SD 48(10.75) & 4 & 1 & 1 & $\mathrm{i}, \mathrm{f}, \mathrm{d}$ \\
\hline Lago et al. $^{45}$ & 2021 & R Case series & 4 & median+SD 64(5.6) & 2 & 1 & 1 & - \\
\hline Lerum et al. ${ }^{46}$ & 2021 & P Cohort & 103 & median+IQR 59(49-72) & 3 & 1 & 0 & $i, f, d, r$ \\
\hline Li, R., et al. ${ }^{47}$ & 2020 & R Cohort & 53 & mean+SD $50.2(15.2)$ & 8 & 1 & 0 & - \\
\hline Li, X. et al. ${ }^{48}$ & 2021 & P Cohort & 289 & mean+SD 43.6(17.4) & 6 & 1 & 1 & $i, f, d, r$ \\
\hline Liang et al. ${ }^{49}$ & 2020 & P Cohort & 76 & mean+SR 41.3 (13.8) & 3 & 1 & 1 & $d, r$ \\
\hline Liu C., et al. ${ }^{50}$ & 2020 & R Cohort & 51 & mean+SR 46.6 (13.9) & 2 & NA & 0 & $i, f$ \\
\hline Liu M., et al. ${ }^{52}$ & 2021 & P Cohort & 41 & mean+SD 50(14) & 7 & 1 & 0 & $\mathrm{i}, \mathrm{f}$ \\
\hline Liu, D., et al. ${ }^{51}$ & 2020 & P Cohort & 149 & mean+IQR 43 (36-56) & 1 & 1 & 0 & $\mathrm{i}, \mathrm{f}$ \\
\hline Liu, X. et al. ${ }^{53}$ & 2020 & R Cohort & 99 & $\begin{array}{c}\text { means+SD } 56.13 \\
(20.7)\end{array}$ & 2 & 1 & 1 & - \\
\hline Lombardi et al. $^{54}$ & 2021 & P Cohort & 86 & mean+SD 58(13) & 1 & 1 & 1 & $d, r$ \\
\hline Lv et al. ${ }^{55}$ & 2020 & R Cohort & 137 & mean+SD 47 (13) & 0.5 & 1 & 0 & - \\
\hline McGroder et al. ${ }^{56}$ & 2021 & p Cohort & 76 & mean+SD 54(13.7) & 4 & 1 & 1 & $\mathrm{i}, \mathrm{f}$, \\
\hline Miwa et al. ${ }^{57}$ & 2021 & R Case series & 17 & median+IQR 63(59-67) & 3 & 2 & 1 & - \\
\hline Morin et al. ${ }^{58}$ & 2021 & P Cohort & 177 & mean+SD 56.9(13.2) & 4 & 1 & 1 & $\mathrm{i}, \mathrm{f}, \mathrm{d}$, \\
\hline Myall et al. $^{59}$ & 2021 & P Cohort & 325 & mean+SD 60.5 (10.7) & 1.5 & 1 & 1 & - \\
\hline Noel-Savina et al. ${ }^{60}$ & 2021 & P Cohort & 72 & mean+SD 60.5(12.8) & 4 & 1 & 0 & $\mathrm{i}, \mathrm{f}, \mathrm{d}, \mathrm{r}$ \\
\hline $\begin{array}{c}\text { Núñez-fernández et } \\
\text { al. }^{61}\end{array}$ & 2021 & P Cohort & 225 & median+IQR 62(50-71) & 3 & 1 & 0 & $d, r$ \\
\hline Polese et al. ${ }^{62}$ & 2021 & P Cohort & 41 & mean+SD 51(14) & 1 & 2 & 1 & - \\
\hline Qin, W. et al. ${ }^{63}$ & 2021 & P Cohort & 81 & mean+SD 59(14) & 3 & 1 & 1 & $i, f, d, r$ \\
\hline Raman et al. ${ }^{64}$ & 2021 & P Cohort & 58 & mean+SD 55.4(13.2) & 3 & 1 & 0 & $r$ \\
\hline Ramani et al. ${ }^{65}$ & 2021 & P Case series & 28 & mean+SD 55.5 (11.9) & 1.5 & 2 & 0 & $d, r$ \\
\hline
\end{tabular}


medRxiv preprint doi: https://doi.org/10.1101/2021.03.15.21253593; this version posted September 17, 2021. The copyright holder for this preprint (which was not certified by peer review) is the author/funder, who has granted medRxiv a license to display the preprint in perpetuity.

It is made available under a CC-BY-NC-ND 4.0 International license .

\begin{tabular}{|c|c|c|c|c|c|c|c|c|}
\hline Santus et al. ${ }^{70}$ & 2021 & P Cohort & 20 & mean+SD 58.3(15.5) & 1.5 & 1 & 0 & - \\
\hline Schandl et al. ${ }^{67}$ & 2021 & P Cohort & 113 & mean+SD 58(12.8) & 6 & 2 & 1 & $d, r$ \\
\hline Shah et al. ${ }^{68}$ & 2020 & P Cohort & 60 & $\begin{array}{c}\text { median+IQR } 67 \text { (54- } \\
74)\end{array}$ & 3 & 1 & 0 & $\mathrm{i}, \mathrm{f}, \mathrm{d}, \mathrm{r}$ \\
\hline Sibila et al. ${ }^{69}$ & 2021 & P Cohort & 172 & mean+SD 56.1(19.8) & 3 & 1 & 0 & $d, r$ \\
\hline Smet et al. ${ }^{70}$ & 2021 & $\begin{array}{l}\text { P Cross- } \\
\text { Sectional }\end{array}$ & 220 & mean+SD 53 (13) & 1.5 & 1 & 0 & $\mathrm{i}, \mathrm{d}, \mathrm{r}$ \\
\hline Strumiliene et al. $^{71}$ & 2021 & P Cohort & 51 & mean+SD 56(11.72) & 2 & 1 & 0 & $\mathrm{i}, \mathrm{f}, \mathrm{d}, \mathrm{r}$ \\
\hline Tabatabaei et al. $^{72}$ & 2020 & R Cohort & 52 & mean+SD 50.17 (13.1) & 3 & 1 & 1 & $\mathrm{i}, \mathrm{f}$ \\
\hline van der Sar et al. ${ }^{73}$ & 2020 & P Cohort & 101 & mean+SD 66.4(12.6) & 1.5 & 1 & 0 & $, \mathrm{~d}, \mathrm{r}$ \\
\hline van Gassel et al. $*^{74,75}$ & 2020 & P Cohort & 46 & $\begin{array}{c}\text { median+ IQR } 62 \text { (55- } \\
68)\end{array}$ & $7^{*}$ & 2 & 0 & $i, f, d, r$ \\
\hline Wei et al. ${ }^{76}$ & 2020 & R Cohort & 59 & $\begin{array}{c}\text { mean+range } 41 \text { (25- } \\
70)\end{array}$ & 0.5 & 0 & 1 & $\mathrm{i}, \mathrm{f}$ \\
\hline $\mathrm{Wu}, \mathrm{Q}$. et $\mathrm{al}^{77}$ & 2021 & P Cohort & 54 & mean+SD 48(15.4) & 6 & 1 & 1 & $i, f, d, r$ \\
\hline Wu, X. et al. ${ }^{78}$ & 2021 & P Cohort & 83 & median+IQR 60(52-66) & 12 & 2 & 0 & $i, f, d, r$ \\
\hline Yasin et al. $^{79}$ & 2021 & R Cohort & 210 & mean+SD 53.85(24.8) & 2 & 1 & 0 & $\mathrm{f}$ \\
\hline Yu et al. ${ }^{80}$ & 2020 & R Cohort & 32 & $\begin{array}{c}\text { mean+SD } 47.05 \\
(17.85)\end{array}$ & 0.3 & 1 & 1 & $i, f$ \\
\hline Zhang, S. et al. ${ }^{81}$ & 2021 & R Cohort & 50 & median+IQR 57(40-68) & 8 & 1 & 0 & $i, f, d, r$ \\
\hline Zhao et al. ${ }^{82}$ & 2020 & R Cohort & 55 & $\begin{array}{c}\text { mean+SD } 47.74 \\
(15.49)\end{array}$ & 3 & 1 & 0 & $\mathrm{i}, \mathrm{f}, \mathrm{d}, \mathrm{r}$ \\
\hline Zhong et al. ${ }^{83}$ & 2020 & R Cohort & 52 & $\begin{array}{c}\text { mean+SD } 45.46 \\
(13.74)\end{array}$ & 1 & 1 & 1 & $\mathrm{i}, \mathrm{f}$ \\
\hline
\end{tabular}

Table 1 Legend:

Study design: P: prospective; R: retrospective

Severity score: $0=$ mild/moderate cohort, $1=$ mixed cohort, $2=$ severe/critical cohort (e.g. ICU patients)

Selection bias: $0=$ very low/low risk of bias, $1=$ high risk of bias $(<60 \%$ of screened patients were included, unclear inclusion criteria, or strict inclusion criteria, e.g. included only patients with CT scans at follow up)

FU: Follow-up in months

Quantitative synthesis, outcomes reported: $i$ : radiological inflammatory findings; $f$ : radiological fibrotic findings; $r$ : functional restrictive impairment; d: functional diffusion impairment; 
Records identified through database

$$
\text { searching }
$$$$
(n=8321)
$$

EMBASE $=6067$

MEDLINE $=2254$
Additional records identified through bibliographies, hand searches, Google Scholar

$$
(n=8)
$$

Records after duplicates removed ( $n=7854$ )

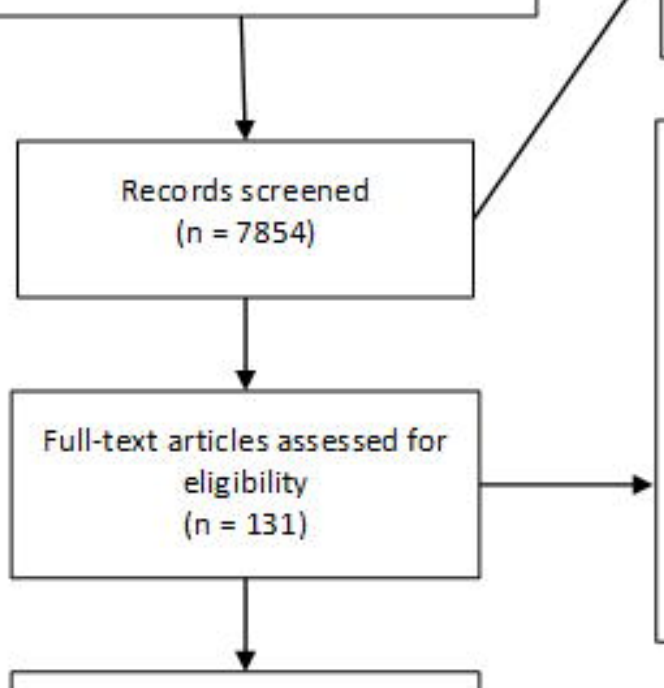

Studies included in qualitative synthesis ( $n=95$ )

Radiological outcome $(n=70)$ Functional outcome $(n=64)$

Studies included in quantitative synthesis $(n=70)$

Radiological outcome ( $n=46$ ) Inflammatory ( $n=42)$

Fibrotic $(n=45)$

Functional outcome $(n=50)$

Restrictive $(n=39)$

Altered diffusion ( $n=44$ )
Records excluded

$$
(n=7723) \text { : }
$$

Excluded on titles $(n=7631)$

Excluded on abstracts $(n=92)$

Full-text articles excluded

$$
(n=36)
$$

Review article $(n=3)$

Letter to the editor $(n=5)$

Tests performed only during hospitalization ( $n=12)$

Poster abstract $(n=4)$

Outcomes not reported $(n=3)$

Patients $<18$ yo included $(n=2)$

Outpatients included ( $n=5)$

Same cohort of other papers included $(n=2)$
Studies excluded

Radiological outcome ( $n=24)$

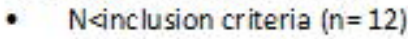

- Reported only qualitative comments $(n=6)$

- Time of Follow up unspecified $(n=1)$

- Incompatible radiological classification $(n=5)$

Functional outcome $(n=14)$

- $N$ <inclusion criteria $(n=7)$

- Reported only qualitative $(n=3)$

- Reported mean values $(n=4)$ 


\section{Inflammatory}

Study

ES $(95 \% \mathrm{Cl})$

n_N Month

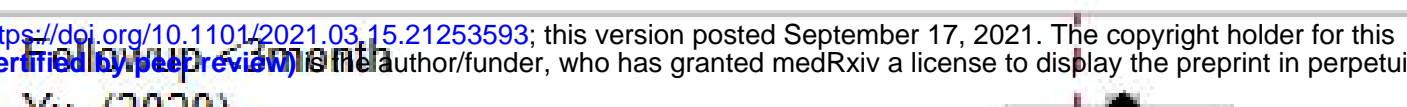
Yu (20102ade avalable
Wei (2020)
Barisione $(2021)$
Zhong (2020)

Liu, D. (2020)

Strumiliene (2021)
Liu, C. (2020)

iX. (2021)

Subtotal ( $(122=96.74 \%, p=0.00)$

Followup 3-6month
Gianella (2021)

Gianella (2021)

van Gassel (2020)

Tabatabaei (2020)

Zhao $(2020)$
Shah (2020)

Cao et al. (2021)

Gonzalez (2021)

Froidure (2021)

Frija-Masson (2021)

Labarca (2021)

Noel-Savina (2021)

McGroder (2021)
Morin (2021)

Wu, Q. (2021)

Han (2021)
Huang. C. (2021)

Huang, C. (2021)
Subtotal $\left({ }^{\wedge} 2=93.63 \%, p=0.00\right)$

Followup >6month

Zhang S. (2021)

Wu, $\mathrm{X} .(2021)$
Subtotal $(1 \times 2=\%, \mathrm{p}=$

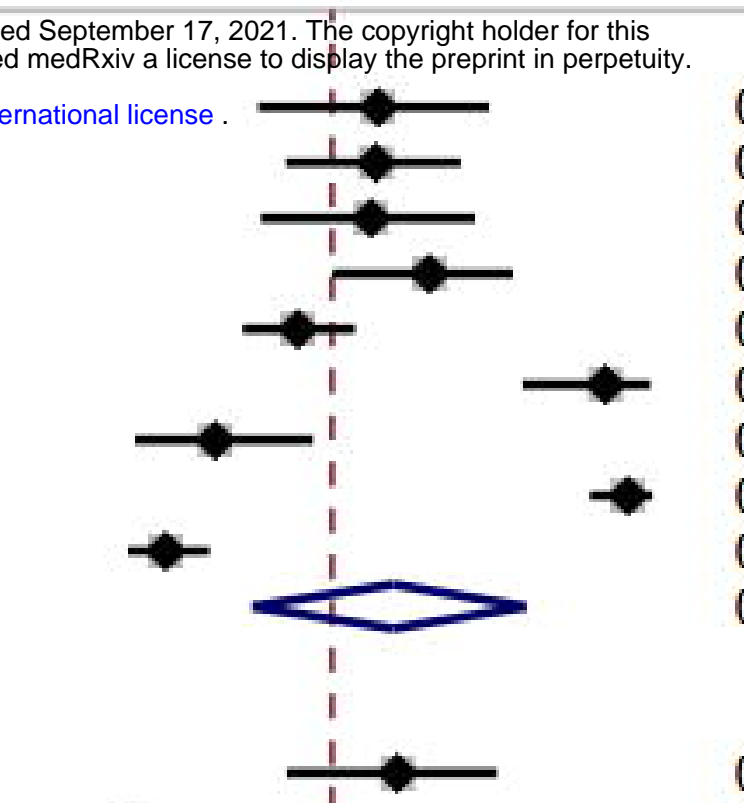

$0.56(0.39,0.72)$

$18 / 32$

$0.55(0.40,0.70$

$0.63(0.50,0.75)$
$0.45(0.37,0.53)$

$0.88(0.77,0.94$

$0.33(0.22,0.47)$

$21 / 38$
$33 / 52$
$67 / 149$

$.26(0.21,0.33)$
$.58(0.39,0.77)$

$45 / 51$
$17 / 51$

$17 / 51$
$149 / 163$
$58 / 220$

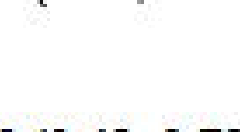

23/39 3

$0.20(0.11,0.34)$

$0.37(0.25,0.50)$

$0.13(0.06,0.24)$

$0.85(0.74,0.92)$
$0.52(0.40,0.64)$

$0.55(0.43,0.67)$

$0.24(0.17,0.33)$

$0.75(0.67,0.82)$

$0.60(0.44,0.73)$
$0.75(0.62,0.85)$

$0.46(0.35,0.57)$

$0.42(0.35,0.49)$

$0.19(0.10,0.32)$

$0.27(0.20,0.36)$

$0.45(0.40,0.51)$
$0.49(0.39,0.59)$

$\begin{array}{ll}9 / 45 & 3 \\ 41 / 46 & 3 \\ 19 / 52 & 3 \\ 7 / 55 & 3 \\ 51 / 60 & 3 \\ 32 / 61 & 3 \\ 34 / 62 & 3 \\ 25 / 103 & 3 \\ 73 / 107 & 3 \\ 103 / 137 & 3 \\ 25 / 12 & 4 \\ 39 / 52 & 4 \\ 33 / 72 & 4 \\ 33 / 76 & 4 \\ 72 / 172 & 4 \\ 9 / 48 & 6 \\ 31 / 114 & 6 \\ 158 / 348 & 6 \\ & \end{array}$

$0.12(0.05,0.26)$

$5 / 41 \quad 7$

$0.23(0.37,0.67)$

$\begin{array}{ll}5 / 41 & 7 \\ 21 / 40 & 8 \\ 19 / 83 & 12\end{array}$

Heterogeneity between groups: $p=0.124$

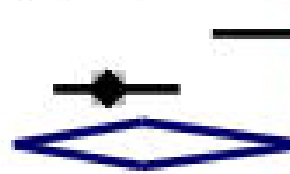

$.50(0.41,0.58)$
Fibrotic

Study

ES $(95 \% \mathrm{Cl})$

n_N $\quad$ Month

Followup <3mont

Yu (2020)

Barisione (2021)

Zhong (2020)
Huang Y. (2020)

Liu, D. (2020)

Strumiliene (202
Liu, C. (2020)

LiX. (2021)

Yasin $(2021)$
Subtotal $(1 \times 2=95.58 \%, p=0.00)$

Followup 3-6month

Gianella (2021)

Qin (2021)
van Gassel (2020)

Tabatabaei (2020)

Zhao (2020)

Cao et al. (2021)

Gonzalez (2021)

Lerum (2021)

Frija-Masson (2021)

Labarca (2021)

Noel-Savina (2021)

McGroder (2021)

Boari (2021)

Morin (2021)

Han (2021)

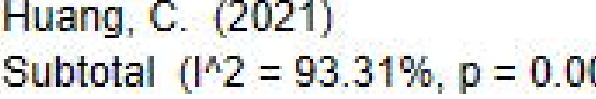

Followup $>6$ month

Zhang S. (2021)

Wu, X. (2021)

Subtotal (1 $12=\%, \mathrm{p}=$.)

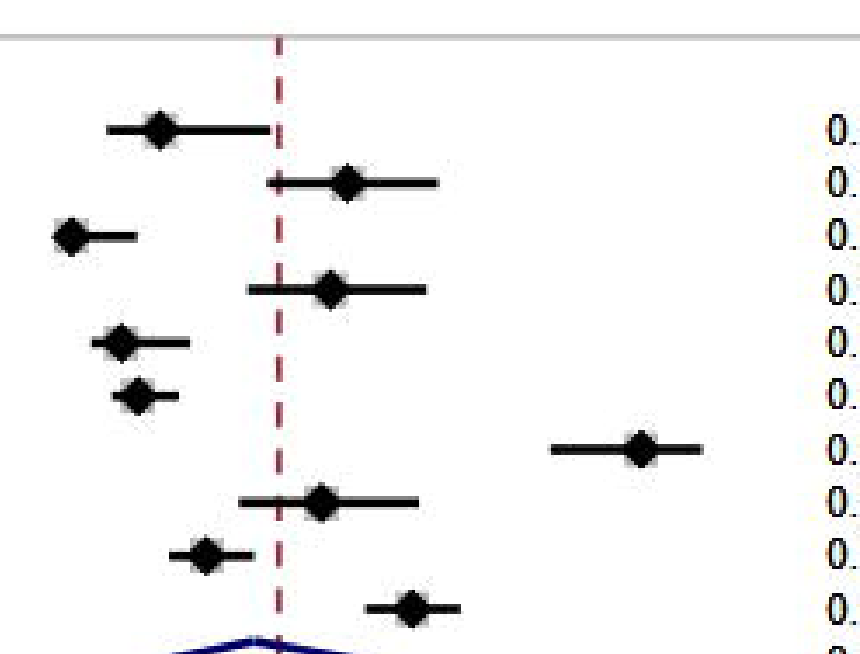

$0.13(0.05,0.28)$

$0.00(0.00,0.09)$

$.37(0.25,0.50)$
$.07(0.03,0.17)$

$09(0.06,0.15)$

$30(0.68,0.89)$
$35(0.24,0.49)$

$41 / 51$

- $\quad 31 / 163$

$0.48(0.41,0.55)$
$0.26(0.13,0.41)$

$101 / 210$

Heterogeneity between groups: $p=0$
Overall $\left({ }^{\wedge} 2=94.06 \%, p=0.00\right)$;

Heterogeneity between groups: $p=0$
Overall $\left({ }^{\wedge} 2=94.06 \%, p=0.00\right)$;

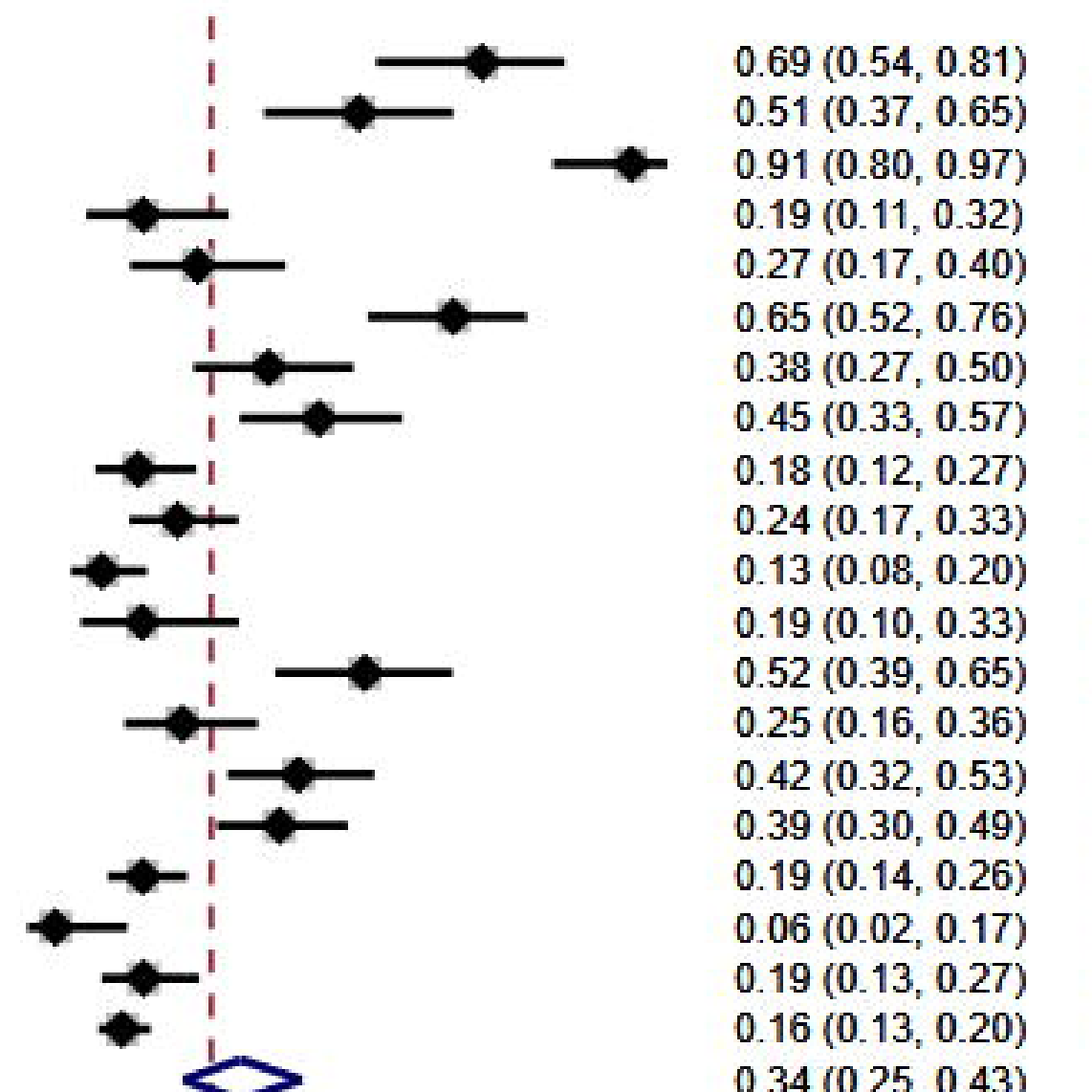

$\begin{array}{ll}27 / 39 & 3 \\ 23 / 45 & 3 \\ & 42466\end{array}$

28162

$26 / 1107$
$18 / 137$

33172

22114

$0.34(0.25,0.43)$

$0.41(0.28,0.57)$

$0.05(0.02,0.12)$

$\begin{array}{ll}17741 & 7 \\ 2 / 40 & 8 \\ 4 / 83 & 12\end{array}$

$0.29(0.22,0.37)$ 


\section{Inflammatory}

Baseline

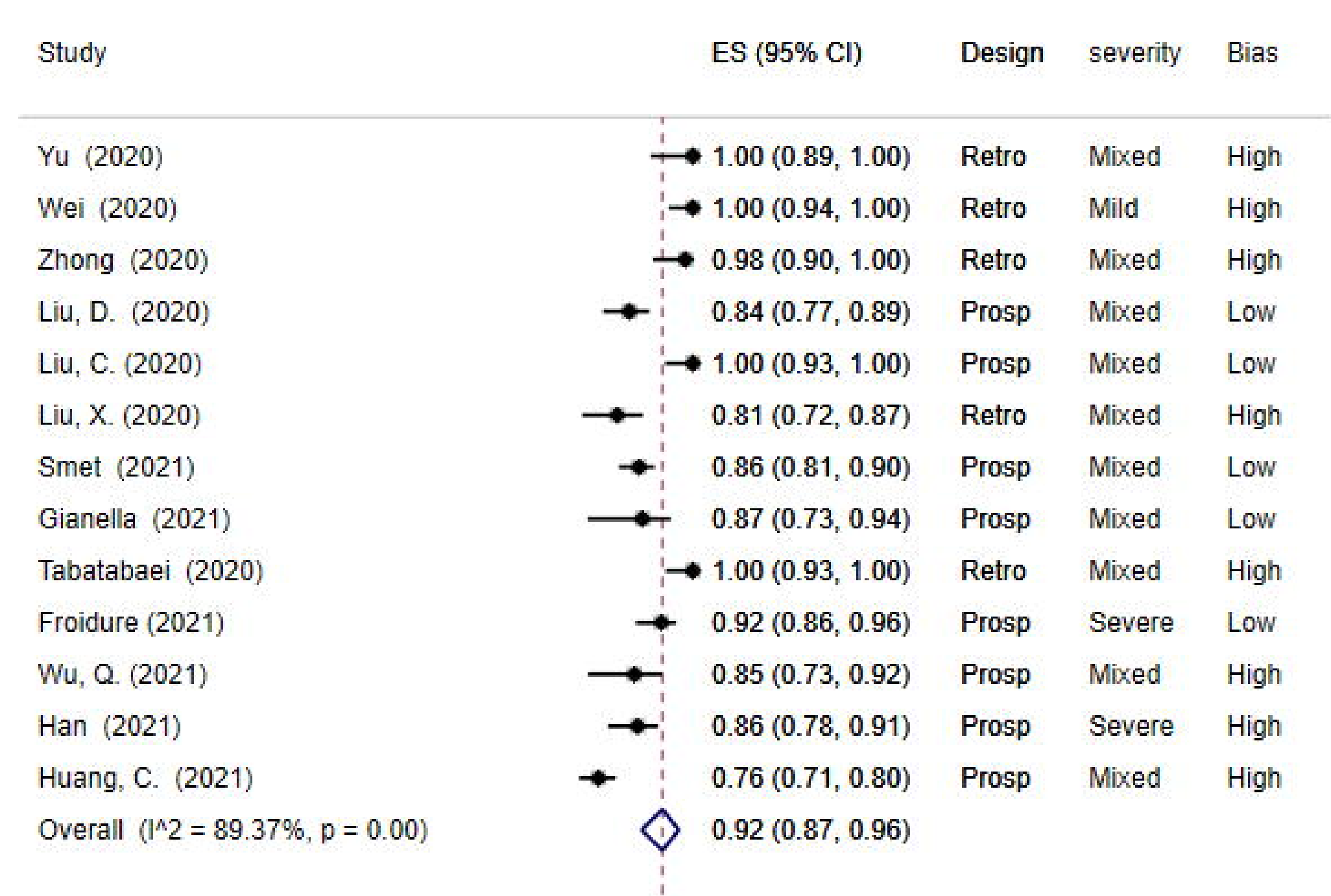

Follow-up

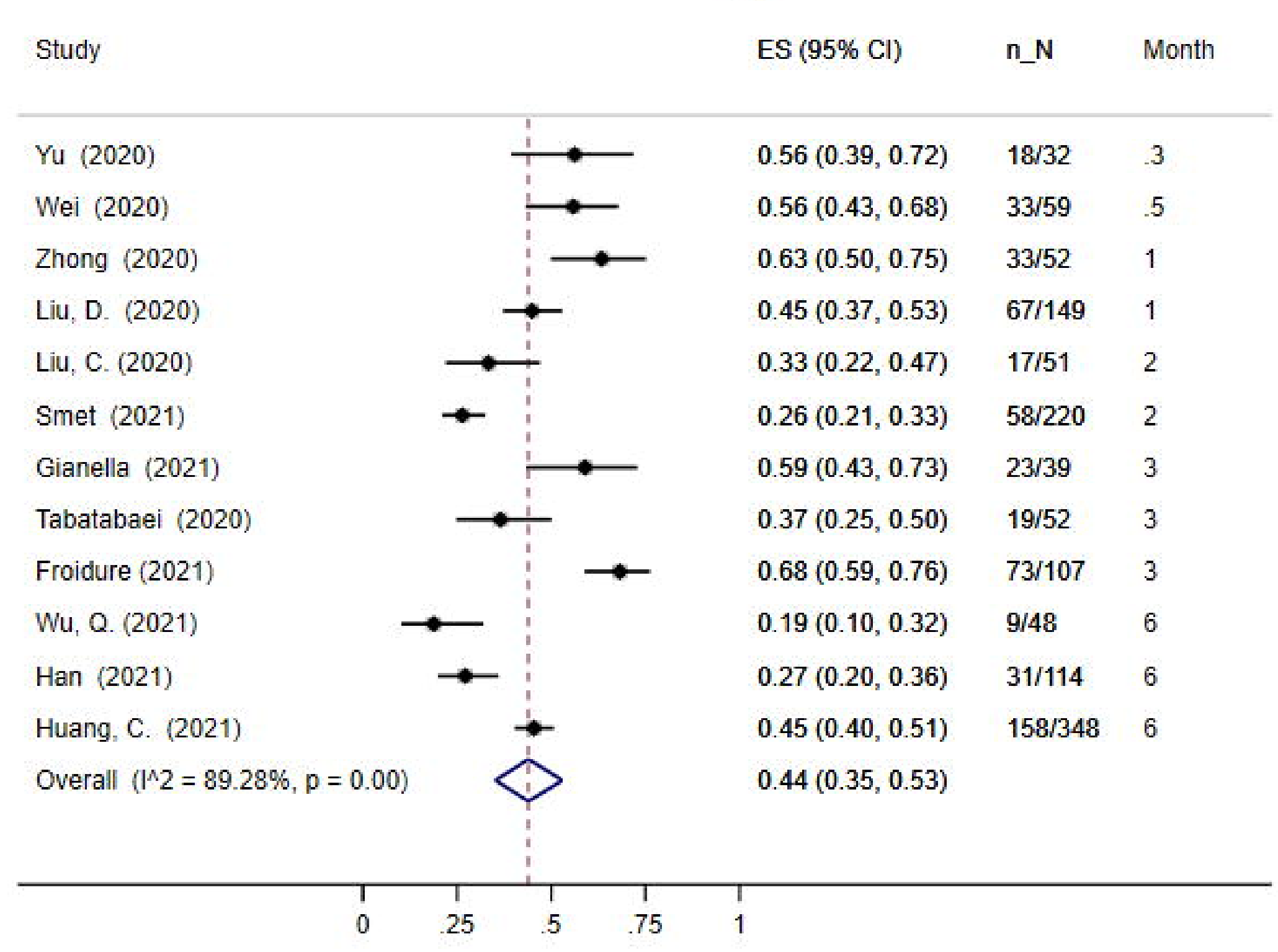

Difference in estimate

\begin{tabular}{|c|c|c|}
\hline Study & Year & Diff $(95 \% \mathrm{Cl})$ \\
\hline Yu & $\rightarrow-$ & $-0.44(-0.61,-0.27)$ \\
\hline Wei & 2020 & $-0.44(-0.57,-0.31)$ \\
\hline Zhong & 2020 & $-0.35(-0.48,-0.21)$ \\
\hline Liu, D. & 2020 & $-0.39(-0.49,-0.29)$ \\
\hline Liu, C. & 2020 & $-0.67(-0.80,-0.54)$ \\
\hline Smet & 2021 & $-0.60(-0.67,-0.53)$ \\
\hline Gianella & 2021 & $-0.28(-0.47,-0.10)$ \\
\hline Tabatabaei & 2020 & $-0.63(-0.77,-0.50)$ \\
\hline Froidure & 2021 & $-0.24(-0.34,-0.14)$ \\
\hline Wu, Q. & $\rightarrow-$ & $-0.66(-0.81,-0.52)$ \\
\hline Han & 2021 & $-0.59(-0.69,-0.48)$ \\
\hline Huang, C. & 2021 & $-0.31(-0.38,-0.24)$ \\
\hline \multicolumn{2}{|c|}{ Overall (I-squared $=87.7 \%, p=0.000)$} & $-0.47(-0.56,-0.37)$ \\
\hline
\end{tabular}




\section{Fibrotic}

Baseline

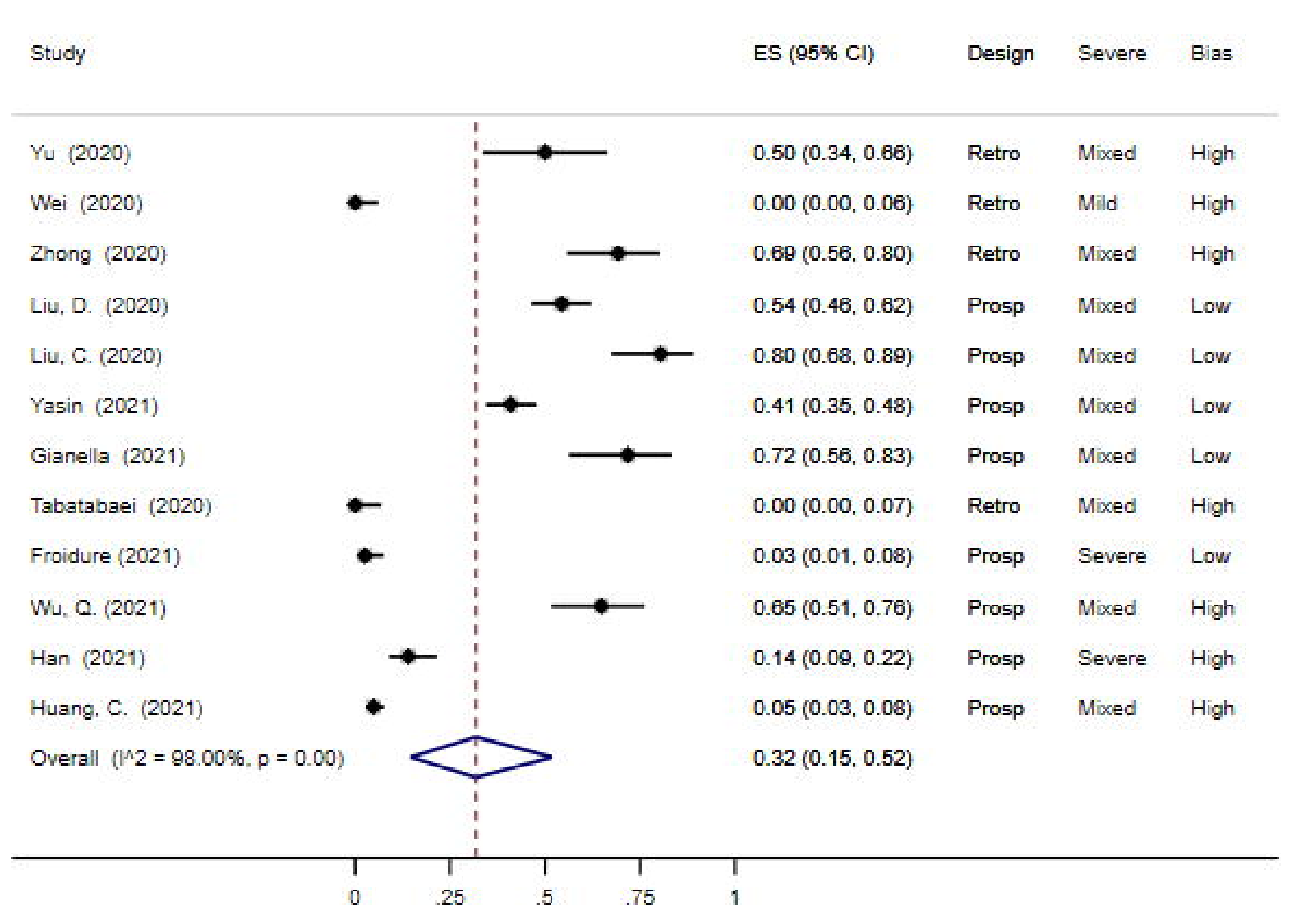

Follow-up

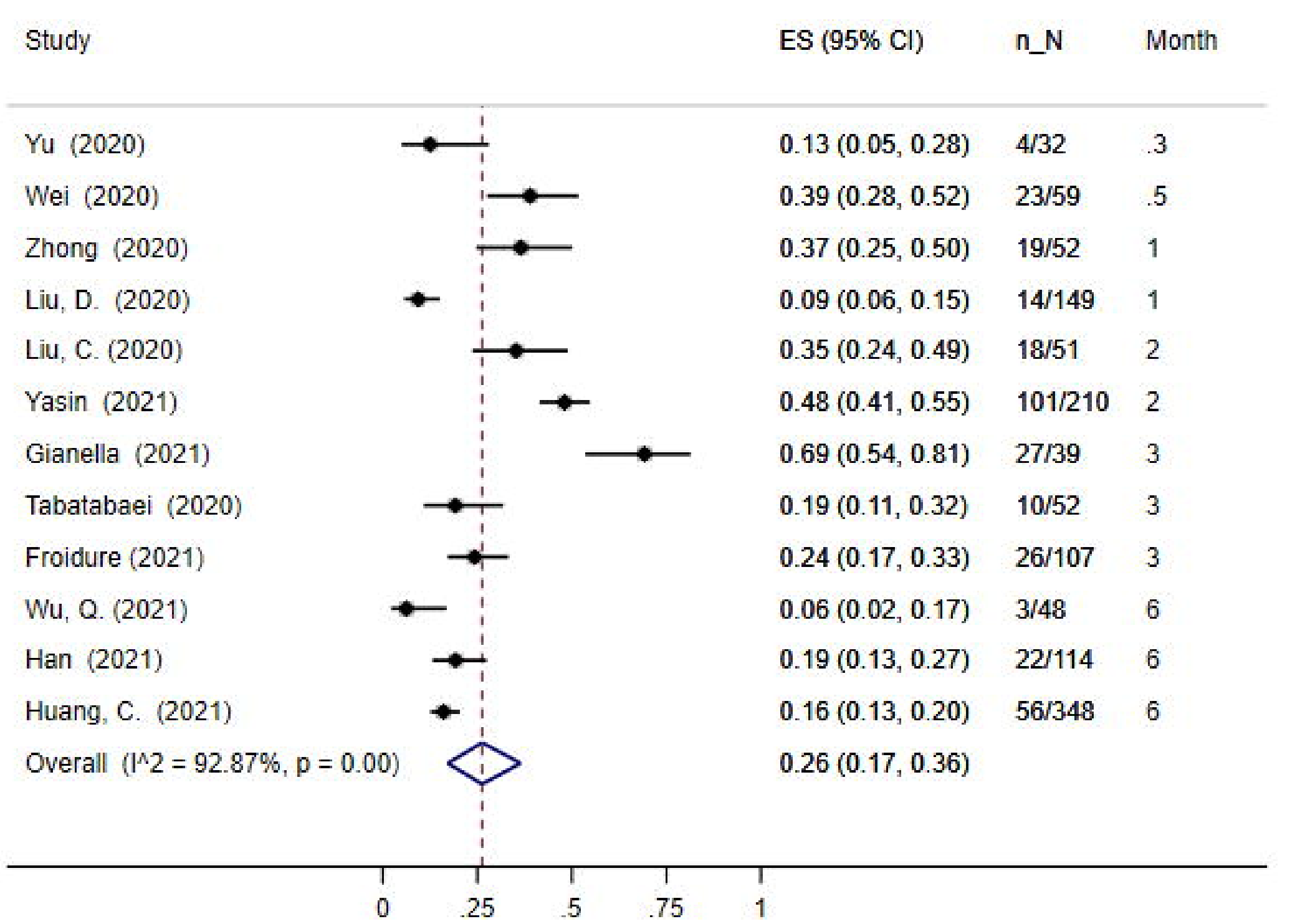

Difference in estimate

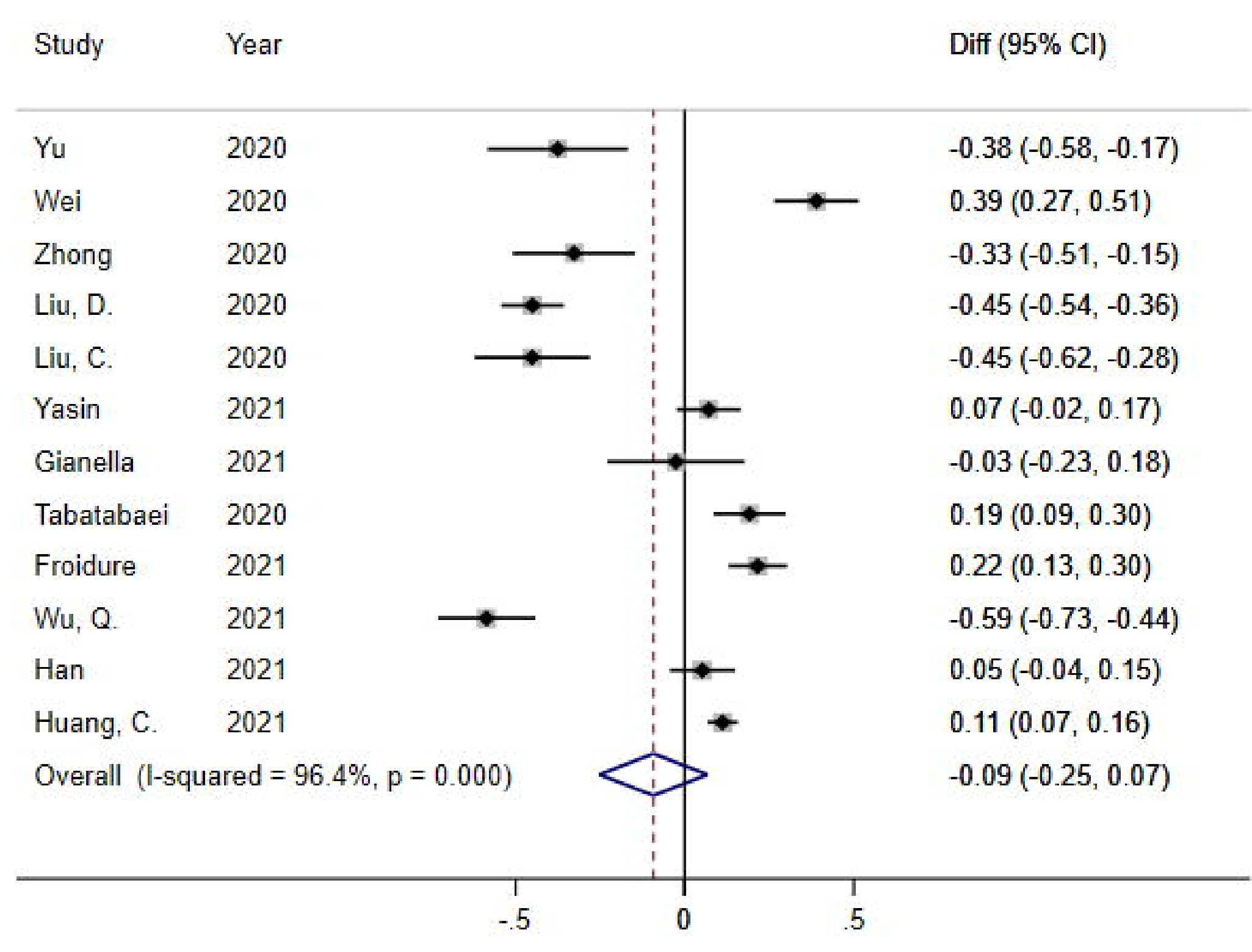


Impaired gas transfer

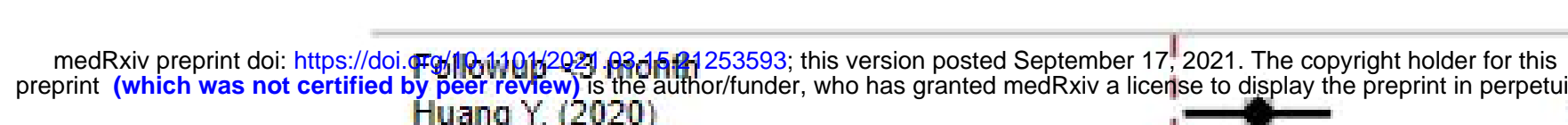

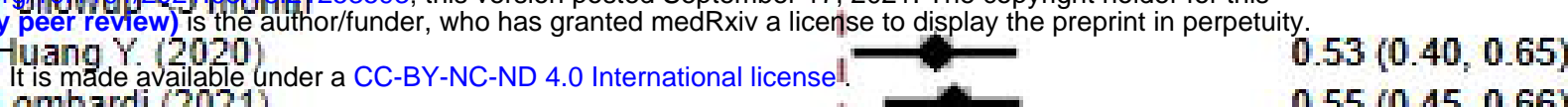
Barisione (2021)
Ramani (2021) Daher. (2020)
van der Sar (2020) van der Sar (2020)
Strumiliene (2021) Smet (2021) Subtotal $\left(\mu^{\wedge} 2=9530 \%, p=0.00\right)$ Followup 3-6 month Zhao et al. (2020) Liang (2020) Lerum (2021) Froidure (2021) Frija-Masson (2021) Nưñez-Fernández (2021) Zhang, S. (2021) Labarca (2021) Ekbom (2021) Crisafulli (2021) Boari (2021) Anastasio (2021) Bellan (2021)
Wu, Q. (2021) Han et al. (2021) Huang C. (2021)
Subtotal $\left(\wedge^{\wedge} 2=91.17 \%, p=0.00\right.$ Followup $>6$ month van Gassel (202
Wu. X. (2021) Subtotal $(122=\%, \mathrm{p}=$.)

$\bullet$ $\because 1-0.32(0.18,0.33)$

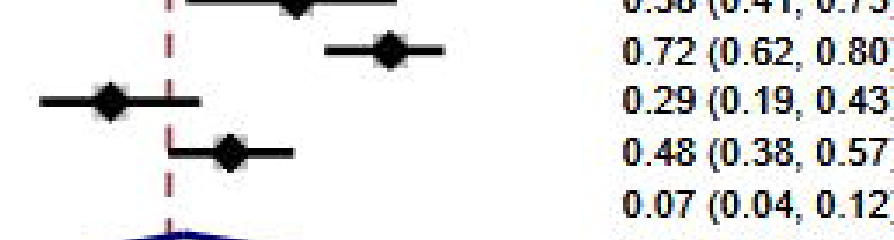
$\begin{array}{ll}30 / 57 & 1 \\ 46 / 83 & 1 \\ 22 / 94 & 1 \\ 9 / 28 & 1 \\ 19 / 33 & 1 \\ 66 / 92 & 15 \\ 15 / 51 & 2 \\ 48 / 101 & 2 \\ 10 / 147 & 2\end{array}$ Heterogeneity between groups: $p=0.54$

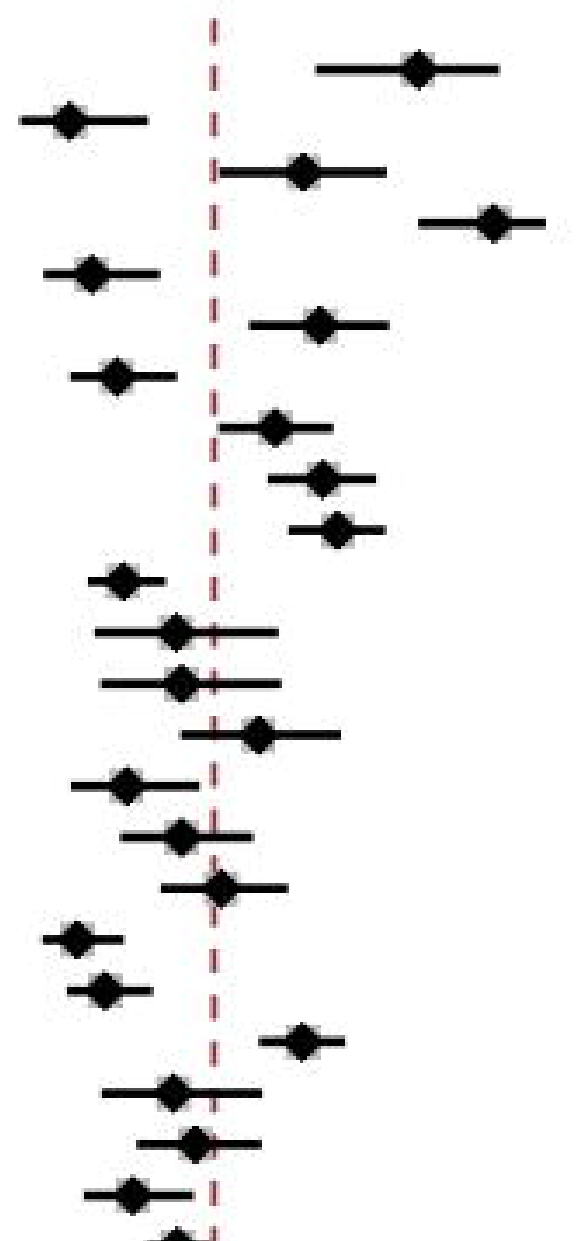

$0.69(0.54,0.8)$ $0.16(0.09,0.28)$ $0.81(0.69,0.89)$
$0.20(0.12,0.30)$
$0.05(0.44,0.55)$ $0.24(0.16,0.33)$ $0.48(0.39,0.56)$ $0.55(0.46,0.63)$ $025(0.19,031)$ $0.32(0.20,0.48)$ $0.33(0.21,0.48)$ $0.25(0.16,0.36)$ $0.33(0.24,0.44)$ $0.39(0.30,0.49)$ $0.17(0.12,0.25)$ $0.52(0.45,0.58)$ $0.32(0.21,0.45)$ $0.35(0.27,0.45)$ $0.26(0.18,0.35)$ $0.38(0.32,0.44)$

$\begin{array}{lll}0.33(0.20,0.47) & 14 / 43 \quad 7 \\ 0.33(0.23,0.43) & 27 / 83 & 7\end{array}$ \begin{tabular}{ll}
1 & $0.33(0.20,0.47)$ \\
\hdashline & $0.33(0.22,0.43)$ \\
\hdashline & $0.23(0.25,0.41)$
\end{tabular}

$0.38(0.32,0.44)$
Restrictive Impairment ES (95\% Cl)

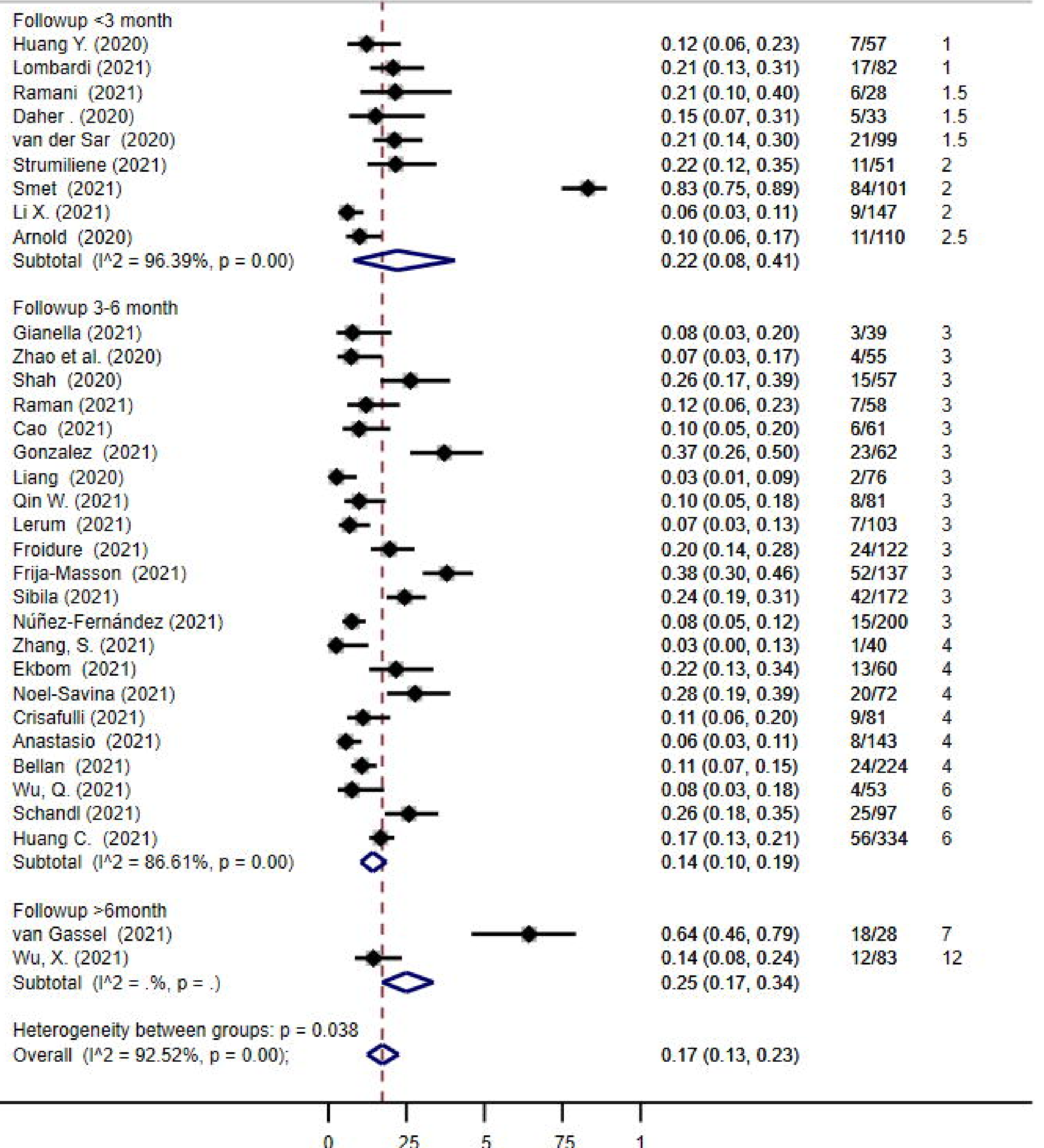

